\title{
Lay-up Optimisation of Fibre-Metal Laminates Panels for Maximum Impact Absorption
}

\author{
Edore G. Arhore*, Mehdi Yasaee \\ School of Aerospace, Transport and Manufacturing, Cranfield University, Cranfield, MK43 OAL, UK \\ edore.arhore@cranfield.ac.uk
}

\begin{abstract}
This paper introduces a methodology utilising a ply-ply damage Finite Element models with Genetic algorithm optimisation procedure to investigate the effect of lay-up configuration on the impact absorption properties of fibre metal laminates (FMLs). The methodology was carried out in two steps. In the first step, a pseudo-2D model was used to explore the vast design space to identify potential optimised layupconfigurations. In the second step, the optimised configurations were studied in full 3D, with high fidelity simulations, verifying the results obtained from the optimisation process. The design variables used include thickness and material (including fibre orientation) of each ply. The results produced an optimised configuration consisting of a metallic ply on the impacted side followed by a cross-ply composite lay-up. The results also suggest that the first composite ply (second ply of the FML) should be about 3 times thicker than the other plies.
\end{abstract}

Declarations of interest: none

\section{Keywords}

Fibre-metal laminate; FML; Genetic algorithm optimisation; Impact energy absorption; ABAQUS

\section{Introduction}

The application of Fibre Reinforced Polymer (FRP) composite materials has increased over the years in different industries. Composite materials are used for aerospace structures due to their high specific strength, stiffness and provide good resistance to fatigue and corrosion. However, composites materials are brittle and therefore susceptible to damage in various forms. As a result of this, foreign object impact on composite structures produces internal damages that are often visually undetectable. 
These internal damages result in the reduction of the strength and stiffness of the composite structure. For this reason, most composite structures in the aerospace applications must be designed to handle service loads even in the presence of barelyvisible impact damage (BVID) [1].

FMLs were initially developed for improved fatigue strength, studies have shown that its impact properties could be better than that of monolithic metals [2]. FMLs could be described as hybrid structures which have an alternating stacking sequence of fibre reinforced polymer-matrix composite and metal layers [3]. These structures can combine the advantageous properties of metals and composites while alleviating their disadvantages [4]. As a result, they are more durable with higher fatigue and fracture properties compared to their constituent materials [3]. This and other advantages have given it wide attention in the aerospace industry [5]. Various classes of FMLs have been developed over the years as well as its application. An example is GLARE which is currently in use for the upper fuselage of Airbus A380 and titanium-based FML wings being developed by Boeing [6].

Impact damage could be classed as one of the most important types of failure in aircraft structures. Sadighi, Alderliesten and Benedictus [7] reported that about 13\% of the fuselage damages repaired are impact damages. These impact damages could occur at various times during operation and maintenance. This outlines the importance of understanding the impact properties of FMLs. Improved impact properties could lead to the development and further application of FMLs in the out warding facing components of aircraft vehicles.

The complex and large number of failure mechanism in FMLs provides a good avenue to manipulate and thus improve energy absorption properties. Research has shown that this property is dependent on four parameters which include the thickness, fibre direction, constituents and composite volume fraction [8].

Cortes [9] carried out a tensile test on FMLs and its constituent materials and showed that the properties of FMLs could be determined using the rule of mixture (ROM) which was developed by Wu et al [10]. They carried out experimental and analytical studies to determine the possibility of predicting the properties of FMLs using the volume fraction of the metal and composite components. The tensile strength, tensile modulus, compressive yield strength and compressive modulus all showed a linear 
relationship to the volume fraction of the metal and composite materials. However, the yield strength was noticed to behave independently to the volume fraction of the constituent materials. This showed that the ROM could not be used to predict all the properties of FMLs. Cortes [9] used ROM and experiments to investigate aluminium based FMLs. The results show that the specific absorbed energy required to perforate the laminate was dependent on the composition of the constituent materials. It was discovered that the peak impact energy for perforation occurred at a composite volume fraction of 0.6. This agreed with the findings of an analytical study carried out by Ghasemi [11]. The results also showed that the position of the metal/composite plies significantly affected the impact property. The best impact property was obtained from specimens with metallic outer plies.

Kaboglu et al. [12] carried out experiments to study the effect of the thickness of the laminate on the impact properties of FMLs. The thickness of the laminate was modified by adding more plies while maintaining the typical FML configuration. The results obtained from the experiment showed that increasing the thickness of FMLs had little to no effect on the specific absorbed energy.

Langdon et al. [13] showed that the size and shape of the damage region are dependent on the thickness of the plies. It was noticed that the damage in thicker specimens occurred in the central region of the laminate with the impacted surface exhibiting low displacements. However, the damage in thinner specimens occurred on the surface of the impacted ply. This finding indicates that the individual ply thickness affects the energy absorption properties of a FML laminate. However, the findings of Choi, Wang and Chang [14] suggest that that the individual thickness of the ply does not affect the impact resistance of the laminate. Their results showed that interlaminar failure was the major mode of dissipating low-velocity impact energy.

Further contradictory findings in literature is from Saito et al. [15], which showed that composite laminates comprised of thinner plies exhibit larger delamination areas after impact and therefore absorb higher impact energies. Compression after impact (CAl) test showed that thinner plies also exhibited a higher residual strength. Based on this, it could be assumed that FMLs comprised of thinner composite plies would experience higher delamination and as a result absorb more impact energy. This assumption was studied by Ankush et al. [16]. They carried out experiments on FML laminates with varying metallic ply thickness and constant overall laminate thickness. The results 
obtained from the experiments showed that increasing the thickness of the impacted metallic ply led to a reduction in deformation and matrix cracking and thus energy absorption. However, they also showed that the distribution of the metallic plies also affected the spread of delamination and subsequently the energy absorption properties.

Seyed Yaghoubi, Liu and Liaw [1] investigated the effect of stacking sequence on the impact properties of FMLs. The results showed that the unidirectional and cross-ply specimen provided the least resistance to impact. The quasi-isotropic laminates provided the best impact resistance. It was noticed that at low impact velocities, the energy was absorbed by delamination agreeing with the findings of Cortés and Cantwell [3].

Seyed Yaghoubi and Liaw [17] investigated the effect of layup configuration on the response of FMLs to impact. The results obtained showed that the cross-ply and unidirectional $\left(0^{\circ}\right)$ specimens offered the highest resistance to the impact. This results contradicts the finding made by Seyed Yaghoubi and Liaw [1]. These contradictory results may suggest that experimental configuration such as boundary condition, impactor shape, weights and velocities all affect the response of the laminate. The interfacial strength was also seen to be dependent on the orientation of the composite ply and the deformation of the adjacent aluminium ply. The results suggested that laminates with alternating fibre directions would absorb higher impact energy.

Although some studies carried out vary in the experimental setup (for example impactor's velocity and weight) making comparison difficult, the results have shown that to improve impact energy absorption, various damage mechanisms within an $\mathrm{FML}$ material must be utilized to its full extent. As outlined by Alderliesten et al. [18], the sequence of the damage mechanism of an impacted $F M L$ is:

1. Plastic deformation of the metallic ply

2. Composite matrix of the subsequent composite ply cracking and delamination in the plastically deformed area

3. Fibre and metal crack in the non-impacted side (first crack)

4. Cracking of the impacted side (through crack). 
The highlighted investigations on FMLs have aimed to identify which standard layering configuration produces the highest performance for impact absorption. No study exists which aim to 'optimise' the individual ply thickness and layup configuration for improvement to impact energy absorption. Carrying out an optimisation process like this would be expensive due to the high number of possible configurations to be tested. However, this cost could be reduced using numerical models. Even so, numerical models must be capable to capture the different complex failure mechanisms of FMLs highlighted above.

Numerical studies on FMLs performed by Fan, Guan and Cantwell [19], Tsartsaris et al. [20] and Zhu and Chai [21] on FMLs subjected to low-velocity impact have used a combination of Continuum Damage Models (CDM) to simulate composite failure (Hashin Failure Criterion for composite layers and Johnson-Cook plasticity and failure model for the metallic layers) and Cohesive Zone Models (CZM) to capture delamination damage [8]. The results obtained from these numerical study were all shown to be accurate relative to experimental results with errors of as little as $5 \%$.

This study will be focused on the effect of FRP composite and metal layer thickness and the fibre direction of the laminates on the impact properties of the FMLs. Using the numerical modelling procedures highlighted above, a systematic procedure is presented to find the optimised configuration that takes the most advantage of the various failure modes in FMLs for impact energy absorption whilst minimising the mass of the material. For this study, the authors made sure that the experimental configuration was kept consistent to minimise its effect on the laminates impact property.

This paper would be divided into three parts. Part I will focus on the optimisation procedure applied to a simplified 2D problem in-order to explore the vast design space (part of the novelty of the study). The use of the 2D model would also help in minimising the overall computational cost. In the first part of Part II, the optimised designs are applied in a full-scale 3D configuration which will cover the effect of anisotropic delamination growth behaviour. Finally, in the second part of Part II, the proposed configuration will be validated against experimental results from literature, comparing the performance of the optimised FML produced here against standard FML designs. 


\section{Numerical Model}

For the numerical simulations, it was crucial to achieve a computationally efficient model for application within the optimisation framework. This is particularly challenging given the different failure and damage models implemented in the simulation. Different variations of the model were tested to determine the overall CPU-time and accuracy of the results. The 3D model required on average 5 hours to complete a simulation capturing the major failure mechanisms of FMLs. Therefore, to minimise this cost, it was decided to create a pseudo-2D model using a 3D modelling procedure. This 'strip' model, illustrated in Figure 2-1, effectively takes a thin section of a full-scale 3D model in the width $(x)$ direction. Symmetric boundary condition on the $x$-faces was added which effectively converts the model to a plane strain configuration. For the strip model, the impactor was modelled as a cylinder as shown in Figure 2-1. Error! Reference source not found. shows an assembled strip-model laminate. Each ply was modelled independently with variable thickness and material property to be determined by the genetic algorithm (GA) optimiser. A pinned boundary condition was applied to the right and the left edge of the plate as shown in Error! Reference source not found.

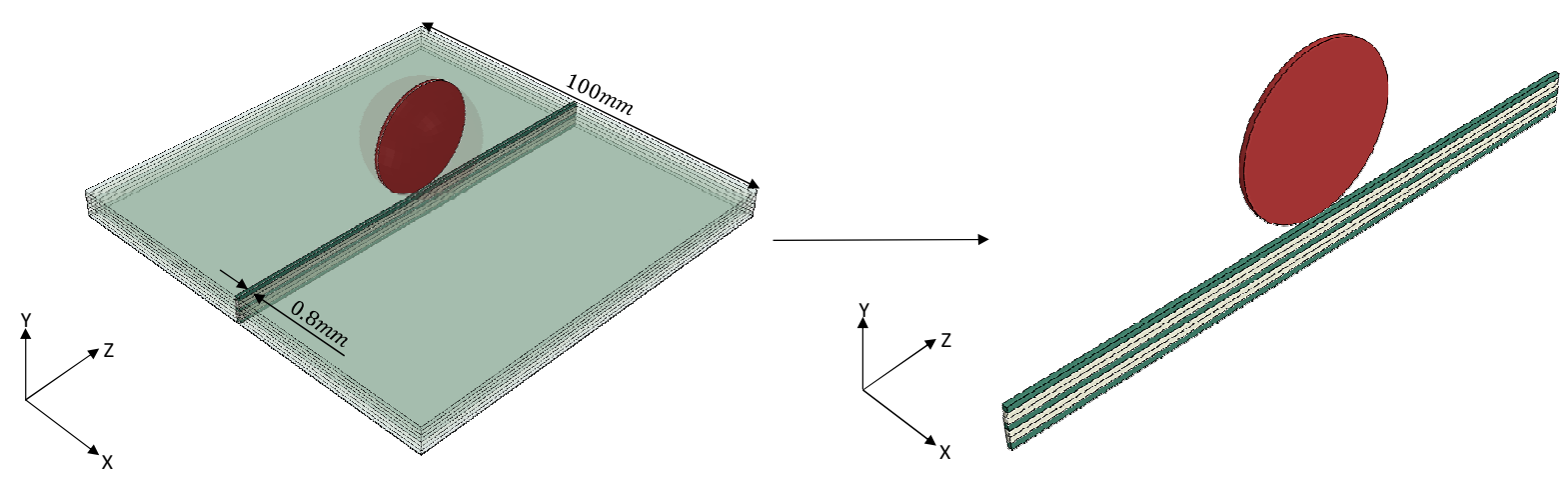

Figure 2-1 Strip model illustration

\subsubsection{Ply Model}

The plies were modelled as rectangular strips with a length of $100 \mathrm{~mm}$ and a width of $0.8 \mathrm{~mm}$. The thickness of each ply $\left(t_{i}\right)$ would be defined by the GA with a lower bound of $0.8 \mathrm{~mm}$ and an upper bound of $1 \mathrm{~mm}$. The plies were modelled as a 3D deformable and meshed using 8-noded solid continuum elements (C3D8) for the metallic layers and 8 noded continuum shell (SC8R) element type for the composite 
plies. To ensure the tubes were suitable for bending load, multiple elements and integration points were used in the thickness direction for the metallic and composite plies respectively. For simplicity only cross-ply and unidirectional laminate layup (only $90^{\circ}$ and $/ 0$ or $0^{\circ}$ fibre direction) were analysed in this paper.

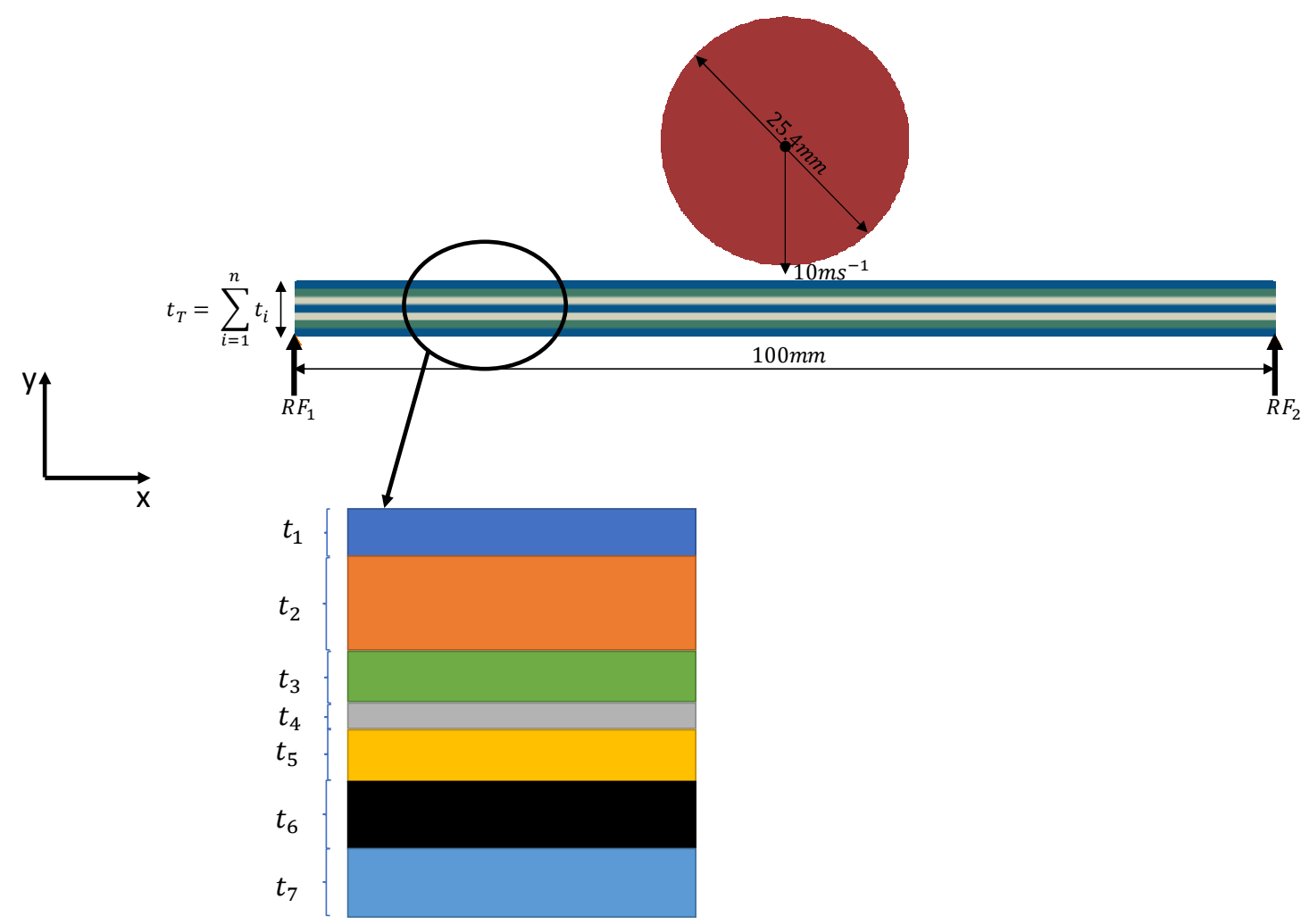

Figure 2-2 Assembled parts

CDM using Johnson-Cook model was used to simulate the plasticity and damage mechanics of the metallic plies. The parameters used for the Johnson-Cook model were obtained from the research work carried out by [22] to ensure it was an empirical fit to the metallic behaviour. Table 1 to Table 3 shows the Aluminium 7075-T6 material properties and input parameters used to model the metallic layers. Equation 2-1 and Equation 2-2 shows the Johnson-Cook equation for plasticity and damage respectively. For this research, the effect of temperature and strain rate were not investigated. As a result, Equation 2-1 and Equation 2-2 were simplified to Equation 2-3 and Equation 2-4 respectively.

$$
\begin{array}{ll}
\sigma=\left(A+B \varepsilon^{n}\right)\left(1+C \ln \dot{\varepsilon}^{*}\right)\left(1-T^{* m}\right) & \text { Equation 2-1 } \\
\varepsilon_{f}^{p}=\left(d_{1}+d_{2} e^{-d_{3} \sigma^{*}}\right)\left(1+d_{4} \ln \dot{\varepsilon}^{*}\right)\left(1-d_{5} T^{*}\right) & \text { Equation 2-2 }
\end{array}
$$




$$
\begin{aligned}
& \sigma=\left(A+B \varepsilon^{n}\right) \\
& \varepsilon_{f}^{p}=\left(d_{1}+d_{2} e^{-d_{3} \sigma^{*}}\right)
\end{aligned}
$$

\section{Table 1}

Elastic Mechanical Properties of Aluminium 7075-T6 [23]

\begin{tabular}{ll}
\hline Parameter & Value \\
\hline Young's modulus $(E)$ & $71.7 \mathrm{GPa}$ \\
Poisson's ratio $(v)$ & 0.33 \\
Mass density $(\rho)$ & $2810 \mathrm{Kgm}^{-3}$ \\
\hline
\end{tabular}

\section{Table 2}

Plastic Johnson-Cook Parameters of Aluminium 7075-T6 [22]

\begin{tabular}{ll}
\hline Parameter & Value \\
\hline$A$ & $473 \mathrm{MPa}$ \\
$B$ & $210 \mathrm{MPa}$ \\
$n$ & 0.3813 \\
\hline
\end{tabular}

\section{Table 3}

Johnson-Cook Damage Parameters of Aluminium 7075-T6 [22]

\begin{tabular}{ll}
\hline Parameter & Value \\
\hline$d_{1}$ & 0.3714 \\
$d_{2}$ & -0.1233 \\
$d_{3}$ & -1.9354 \\
\hline
\end{tabular}

The composite layers were modelled using the orthotropic laminate properties IM7/8552 material listed in Table 4. Failure of the composite layers was simulated using CDM with Hashin Failure Criterion with strength properties given in 
Table 5. The materials used for the optimisation process were selected because they are highly characterised in open literature. This allowed for increased accuracy during the initial modelling setup, calibration and validation process.

\section{Table 4}

Composite IM7/8552 Elastic Properties [24]

\begin{tabular}{ll}
\hline Parameter & Value \\
\hline Young modulus, fibre direction $\left(E_{1}\right)$ & $161 G P a$ \\
Young modulus, transverse direction $\left(E_{2}, E_{3}\right)$ & $11.38 G P a$ \\
In-plane shear modulus $\left(G_{12}, G_{13}\right)$ & $5.17 G P a$ \\
Transverse shear Modulus $\left(G_{23}\right)$ & $3.92 G P a$ \\
Poisson's ratio $\left(v_{12}\right)$ & 0.32 \\
Poisson's ratio $\left(v_{13}\right)$ & 0.32 \\
Poisson's ratio $\left(v_{23}\right)$ & 0.3813 \\
\hline
\end{tabular}

\section{Table 5}

Composite IM7/8552 Strength Properties [24]

\begin{tabular}{ll}
\hline Parameter & Value \\
\hline Tensile strength, fibre direction $\left(X_{T}\right)$ & $2.3 G P a$ \\
Compressive strength, fibre direction $\left(X_{C}\right)$ & $1 G P a$ \\
Tensile strength $\left(Y_{T}\right)$ & $62.3 \mathrm{MPa}$ \\
Compressive strength $\left(Y_{C}\right)$ & $253.7 \mathrm{MPa}$ \\
Shear strength (in-plane), $\left(S_{12}\right)$ & $89.6 \mathrm{MPa}$ \\
Shear strength $\left(S_{23}\right)$ & $126.9 \mathrm{MPa}$ \\
$\alpha$ & 0 \\
\hline
\end{tabular}

\subsubsection{Impactor}

An impactor of a diameter of $25.4 \mathrm{~mm}$ was modelled as a 3D deformable solid cylinder and meshed using 8-noded continuum elements (C3D8). Similar to the beam strip, the 
impactor has a width of $0.8 \mathrm{~mm}$. A rigid constraint was applied to the impactor to ensure some of the impact energy would not be dissipated by the deformation of the impactor. The mass of the impactor was set to $0.15 \mathrm{~g}$ by setting an equivalent density value. The initial kinetic energy of the impactor was set to $0.075 \mathrm{~J}$ by applying an initial velocity of $10 \mathrm{~m} / \mathrm{s}$.

\subsubsection{Interface Property and Mesh Size Calibration}

For all interfaces not in cohesive contact, a general contact interaction property with was set to define the contact between all external surfaces. To simulate delamination, CZM was applied to each dissimilar interface in the plate. To define the cohesive contact between the plies, individual property assignments were added to the contact interaction. The cohesive contact was defined between the plies, using a surface interaction with cohesive behaviour and damage as the contact property options. The stiffness of the cohesive contact was left as its default values (infinitely stiff). The cohesive damage properties for the metal-composite and composite-composite interface are given in Table 6 and Table 7 respectively. Composite-composite interfaces of the same fibre orientation do not fail by delamination, therefore a tie constraint was added in this case.

The interface properties are mesh dependent [25] and therefore had to be calibrated for the chosen mesh element size of $0.4 \mathrm{~mm}$ used for the analysis using experimental data. During the calibration process, the values of the fracture toughness $\left(G_{I C}, G_{I I C}, G_{I I I C}\right)$ were kept constant as the experimentally obtained values. However, the interface strength properties $\left(\sigma_{I}\right.$ and $\left.\sigma_{I I}\right)$ which is mesh dependent were modified in the calibration process. The metal-composite interface properties (Table 6) were extracted directly from literature.

For the Mode I fracture toughness, double cantilever beam (DCB) tests were performed for this study according to ASTM standard D5528 [26]. A unidirectional IM7/8552 laminate made up of 24 plies was used as the test specimen. On the midplane, a PTFE release film of $13 \mu \mathrm{m}$ thickness generates the artificial crack length. The laminate was cured in an autoclave following the manufacturer's recommended curing cycle. Each ply of the cured laminate was nominally $0.125 \mathrm{~mm}$ resulting in a nominal laminate thickness of $3 \mathrm{~mm}$. The laminate plate was machined to extract five specimens with a length of $120 \mathrm{~mm}$ and a width of $20 \mathrm{~mm}$ with a pre-crack length of 
$a=50 \mathrm{~mm}$. Figure 2-3 shows an illustration of the experimental DCB model setup. Steel piano hinges were attached to the surfaces of the laminates for the load application ensuring the load line to the crack tip remains at $50 \mathrm{~mm}$.

A calibrated Inspiron machine with a maximum loading capacity of $5 \mathrm{kN}$ was used to carry out the experiment. The tensile load was applied to the piano hinges (Figure 2-3) at a rate $4 \mathrm{~mm} / \mathrm{min}$ as prescribed in the standard. The force-displacement graph obtained from the 5 specimens is shown in Figure 2-3. Crack length were measured with an accuracy of $\pm 0.5 \mathrm{~mm}$ using a synchronised high definition digital camcorder. Following the ASTM standard, the Mode I fracture toughness $\left(G_{I C}\right)$ calculated from the experiment was $210 \pm 5 \mathrm{Jm}^{-2}$. Mode II fracture toughness properties were taken from end-notched flexure (ENF) tests performed according to ASTM D7905 standard [27] by Yasaee et. al. [28].

The interface strength $\left(\sigma_{I}\right)$ property was calibrated by performing a FEM analysis of the experimental model. Figure 2-3 shows a comparison of the force-displacement graphs obtained from the calibrated FEM model with 5 specimens from the performed DCB experiment.

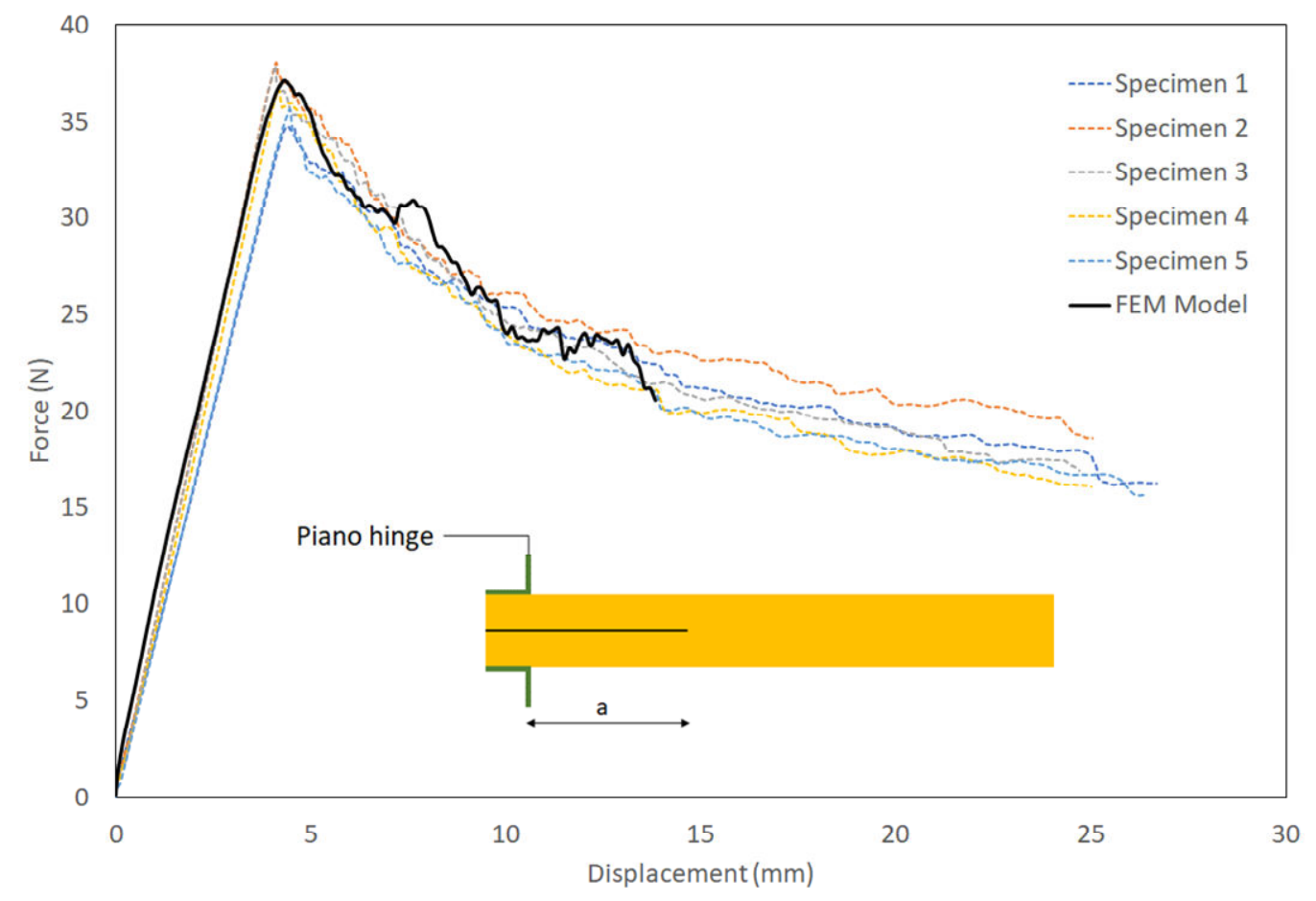

Figure 2-3 Comparison of experimental DCB test specimens and calibrated FEM model 
The interface strength $\left(\sigma_{I I}\right)$ property was calibrated to match the experimental results of [28] for the element size of $0.4 \mathrm{~mm}$. The modelling procedure follows a similar method described in section 2, replicating the ENF tests from [28]. A displacement was applied at the centre of the laminate with roller boundary conditions applied to both edges. A comparison of the force-displacement graphs for the ENF test is shown in Figure 2-4. This graph compares the calibrated FEM model with the experimental results obtained from [28]. While calibrating for the Mode II property, the properties obtained during the Mode I calibration were kept constant.

A summary of the fracture toughness and the calibrated strength parameters are given in Table 7.

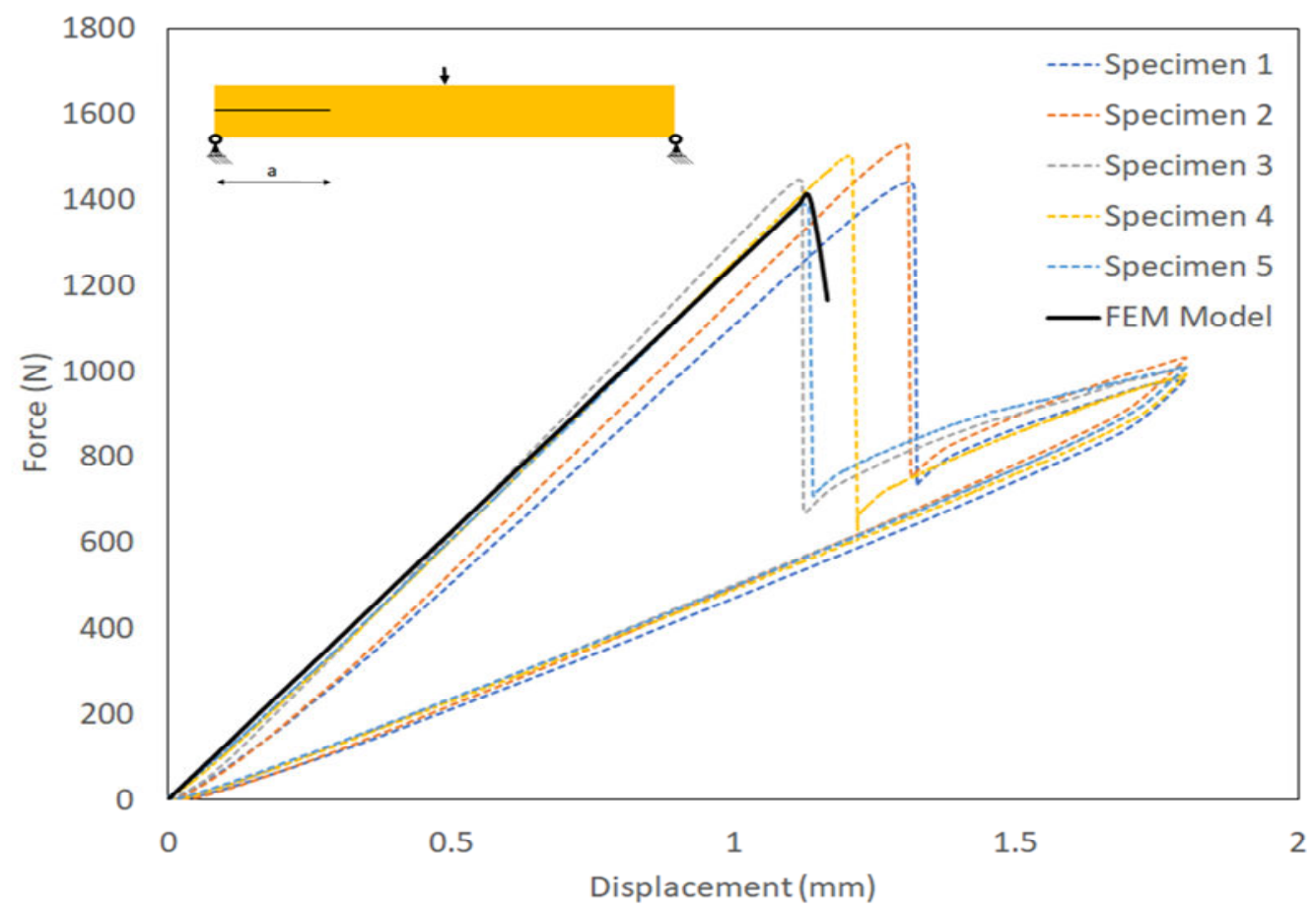

Figure 2-4 Comparison of experimental ENF test specimens and calibrated FEM model

\section{Table 6}

Cohesive Damage Property for Metal - Composite interface [29]

\begin{tabular}{ll}
\hline Parameter & Value \\
\hline$G_{I C}$ & $450 \mathrm{Jm}^{-2}$ \\
$G_{I I C}, G_{I I I C}$ & $1000 \mathrm{Jm}^{-2}$ \\
$\sigma_{I}$ & $40 \mathrm{MPa}$
\end{tabular}




\section{Table 7}

Cohesive Damage Property for Composite - Composite interface [28]

\begin{tabular}{ll}
\hline Parameter & Value \\
\hline$G_{I C}$ & $210 \mathrm{Jm}^{-2}$ \\
$G_{I I C}, G_{I I I C}$ & $663 \mathrm{Jm}^{-2}$ \\
$\sigma_{I}$ & $15 \mathrm{MPa}$ \\
$\sigma_{I I}, \sigma_{I I I}$ & $340 \mathrm{MPa}$ \\
$B K$ exponent & 2.1 \\
\hline
\end{tabular}

\section{Part I: Optimisation Methodology and Results}

GA optimisation toolkit in MATLAB is used to carry out the optimisation of the FML structure. The algorithm works by creating a random initial population with each member matching the dimension of the function (the number of design variables). The good performing members (parents) of the initial population are mutated to create new members (children) to be tested. This process is continued until the optimal design variable is obtained or a stopping condition (example: time-limit) is met. More information on the GA toolkit provided by MATLAB can be obtained from $[30,31]$.

The GA toolkit in MATLAB is set to find the local minimum value to an objective function. For this analysis, the GA function was set to maximise specific absorbed energy ( $S A E$ ) of the panel by minimising its inverse. The objective function used by the GA algorithm was a MATLAB script created to generate a FE model in ABAQUS, submit it for analysis and extract the results from the generated ODB file. Figure 3-1 shows a flowchart of the MATLAB script used.

The design variables used to minimize the objective function include the material (including fibre orientation) and thickness for each ply. Therefore, the number of design variables is two times the total number of plies in the laminate. To reduce the overall time of the optimisation, a constraint function was included to prevent 
consecutive metallic plies. The effect of residual stresses in the laminate was ignored to reduce the number of design variable and optimise runtime. Although this could be included by simply constraining the design variables. It was decided to limit the restrictions of the optimiser allowing it to explore a vast design space within a reasonable computational cost.

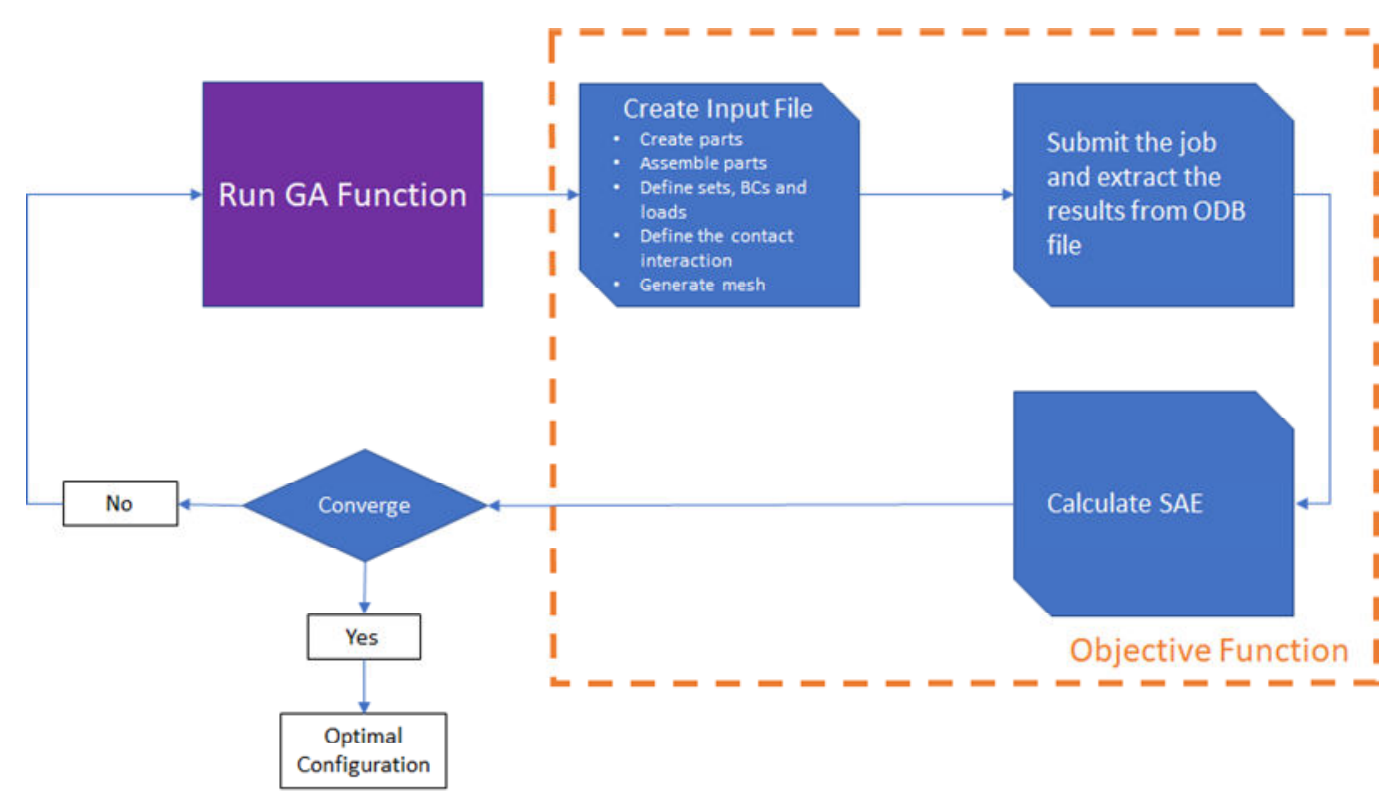

Figure 3-1 Analysis flow chart

The design variables from the genetic algorithm are passed through the objective function. The first part of the objective function generates an ABAQUS input file following the steps shown in Figure 3-1. The input file was created by generating the nodes and connectivity for each ply and the impactor. The generated parts were used to create the laminate assembly with the impactor positioned above the first ply. The contact properties were defined for each consecutive ply. The boundary conditions and load were also applied to laminate as shown in Error! Reference source not found.. Each ply was modelled individually as described in Section 2.

Next, the generated input file was submitted by the script to ABAQUS for analysis. After completion of the analysis, the results are extracted from the ODB file. The absorbed energy ( $\mathrm{AE}$ ) was calculated using the graph of the impactor's contact force against its displacement. This was done by computing the approximate integral of the curve using the trapezoidal method. This method computes the integration by splitting the curve into trapezoids allowing for easier calculation of the area. The SAE value 
was obtained by dividing the calculated AE value with the mass of the laminate and multiplying it by its surface area.

The calculated SAE was returned to the GA optimiser. It should be noted that by default the GA optimisation toolkit minimises the equation. Therefore, the inverse of the obtained SAE was returned. The value was recorded by the algorithm which created new parameters for the objective function. This loop continued until the value of the SAE converged to a maximum.

\subsection{Results}

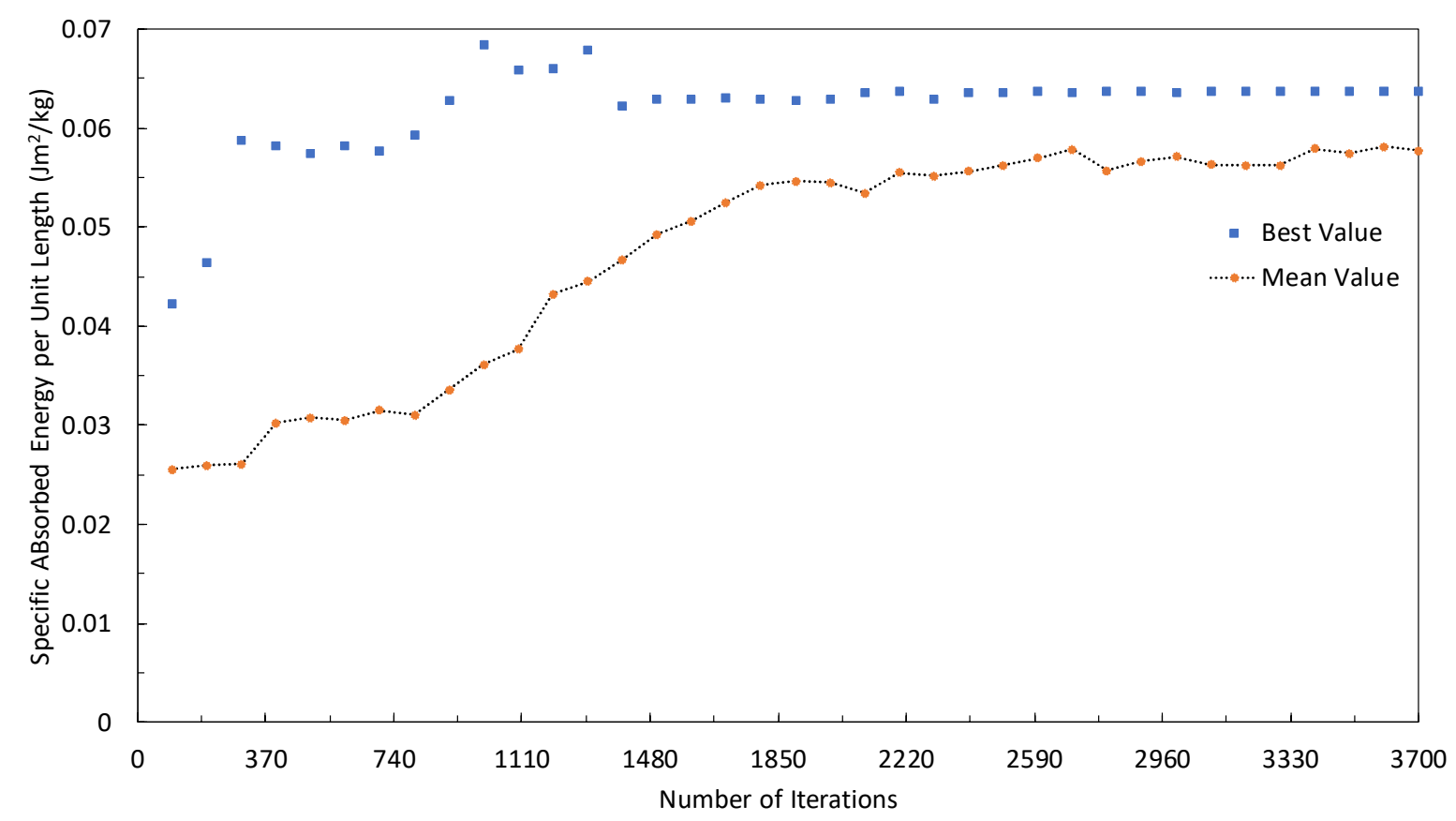

\section{Figure 3-2 Convergence of SAE}

The GA optimiser with the pseudo-2D strip model ran for a total of 3,700 iterations in approximately 720 hours. Figure 3-2 shows the convergence of SAE per unit length values with the increasing number of iteration. It shows the best and mean values obtained from the genetic optimisation for every 100 simulations. From the graph, it can be noticed that the optimal configuration did not exhibit the highest SAE values. The configuration with the highest SAE was obtained at approximately 1000 iterations. The configuration with the highest SAE is shown in Figure 3-3. It would be referred to as GA-1 [M 9090909090 0]. It is interesting to note that there are only two interfaces along which delamination may propagate in this configuration. It can be argued that 
this configuration should not exhibit high energy absorption properties due to the lack of interfaces capable of producing delamination. The reason for the high SAEs could due to the high flexibility of the $90^{\circ}$ block, which provided a significant contribution to the total energy absorption as a consequence of the model setup.

\begin{tabular}{|c|}
\hline Metal \\
\hline Composite $90^{\circ}$ Fibre \\
\hline Composite $90^{\circ}$ Fibre \\
\hline Composite $90^{\circ}$ Fibre \\
\hline Composite $90^{\circ}$ Fibre \\
\hline Composite $90^{\circ}$ Fibre \\
\hline Composite $0^{\circ}$ Fibre \\
\hline
\end{tabular}

\section{Figure 3-3 First GA configuration with maximum SAE (GA-1)}

The optimised configuration [Metal/90/90/90/0/90/0] (GA-2) produced by the GA optimisation procedure is shown in Figure 3-4. Interesting to note, all highperformance configurations consist of a single metallic ply on the impacted side. This means the best utilisation of the plastic deformation of the metallic layer for impact absorption is achieved at this location. The next three layers are UD composite layers with the transverse direction providing flexibility to the geometry, allowing for the metal layer to deform. The outer composite layer, provide the stiffness to the structure with further three interfaces where delamination occurred contributing to the energy absorption.

\begin{tabular}{|c|}
\hline Metal \\
\hline Composite $90^{\circ}$ Fibre \\
\hline Composite $90^{\circ}$ Fibre \\
\hline Composite $90^{\circ}$ Fibre \\
\hline Composite $0^{\circ}$ Fibre \\
\hline Composite $90^{\circ}$ Fibre \\
\hline Composite $0^{\circ}$ Fibre \\
\hline
\end{tabular}

Figure 3-4 Second GA optimised configuration with maximum SAE (GA-2)

Figure 3-5 shows the average SAEs for different configurations simulated during the optimisation process. The GA-3 configuration which consisted of one metallic 
impacted ply and one cross-ply composite laminate produced relatively low SAEs. Although counter-intuitive, this configuration was expected to generate higher SAEs due to the large delamination possibilities in the cross-ply composite layer. The results also showed that a higher number of metallic layers as in the GA-4 configuration will have detrimental effects on the SAE of the structure. Lay-up configurations which included a single metallic ply as the non-impacted ply was also analysed by the GA optimiser. This configuration produced very low energy absorption properties and subsequently very low SAE values. The lowest SAE values were obtained from laminates comprised entirely of unidirectional composite plies.

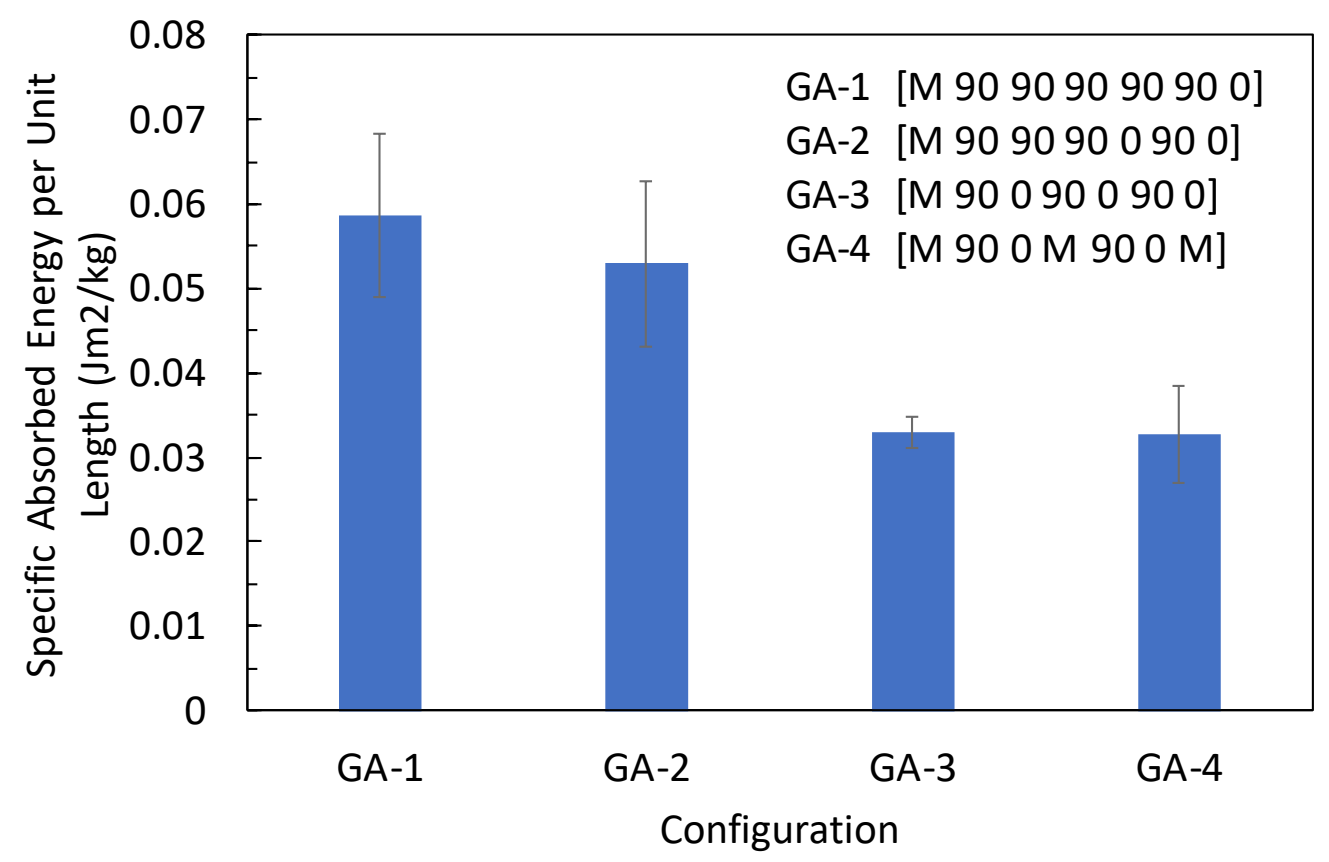

Figure 3-5 Comparison of specific energy absorbed for different configurations

Comparing the change in kinetic energy of the impactor for different configurations could describe how the impact energy was absorbed by the laminates. From the plot (Figure 3-6), it can be seen that delamination was the major mechanism for absorbing the impact energy in the GA-2 configuration. This can be extrapolated from the graph's visual representation of the drop in the impactor's kinetic energy between the initial delamination and first play failure. This configuration also allowed for more energy absorption from the plastic deformation of the metallic ply and elastic deformation and matrix cracking of the transverse UD composite layer before triggering delamination. This allowed the initial delamination to occur at a lower kinetic energy in comparison to the other configurations. Although first ply failure also occurred late in the GA-4 
configuration, the energy absorbing capability was lower than the GA-2 configuration. For this lay-up configuration, the energy absorbed between the initial delamination and first ply failure was about half that absorbed by the GA-2 model. The GA-3 and GA-1 configuration provided a similar response to the impact.

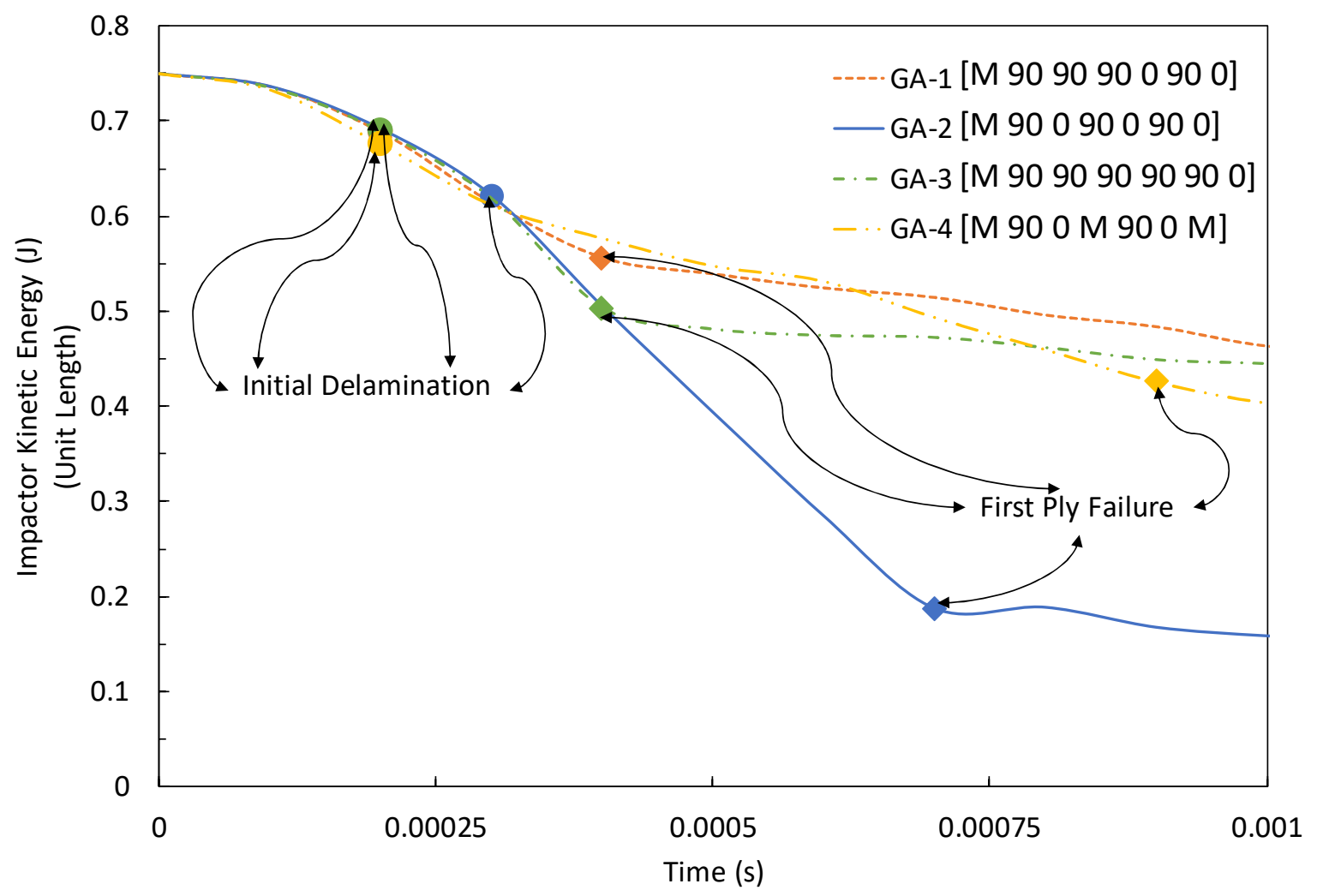

Figure 3-6 Comparison of changes to impactor kinetic energy for different configurations

The results also highlight how the individual thickness of each ply may affect the impact properties of the laminate. To better discuss the effect of the individual ply thickness, the ratio of the thickness of the plies to the overall thickness would be used. Although, the results showed that the effect of the thickness is minimal compared to the effect of the configuration. This could be the result of the similar thickness values used. The results from the optimisation showed that using a thicker metallic ply allows for more energy absorption. This behaviour is similar to the results obtained by Ankush et al. [16]. The optimal configuration converged to the maximum allowed thickness for the impacted metallic ply.

As stated earlier, a tie constraint was applied to consecutive composite plies with uniform fibre direction. Therefore, in comparing the effect of the ply thickness, 
consecutive unidirectional plies were considered a single ply. The results showed that the overall thickness of the unidirectional composite laminate in the GA-2 configuration directly affected the energy-absorbing properties. The thickness of the laminate converged to approximately $44 \%$ of the overall laminate thickness. It was noticed that higher and lower thickness ratios resulted in a drop in the energy absorbed. Changes to the thickness of the first two plies in the cross-ply laminate in the GA-2 configuration did not seem to affect the energy absorption properties. However, the thickness of the third was noticed to affect the SAE value of the laminate. It was noticed that a thickness ratio of $14 \%$ allowed for the most delamination before failure, therefore, increasing the energy absorbed. Figure 3-7 shows the thickness for the best (A) and worst (B) GA-2 configuration based on individual ply thickness. Note that the major difference between both laminates is the thickness of the impacted metallic ply and the 0/90 layers.

(A)

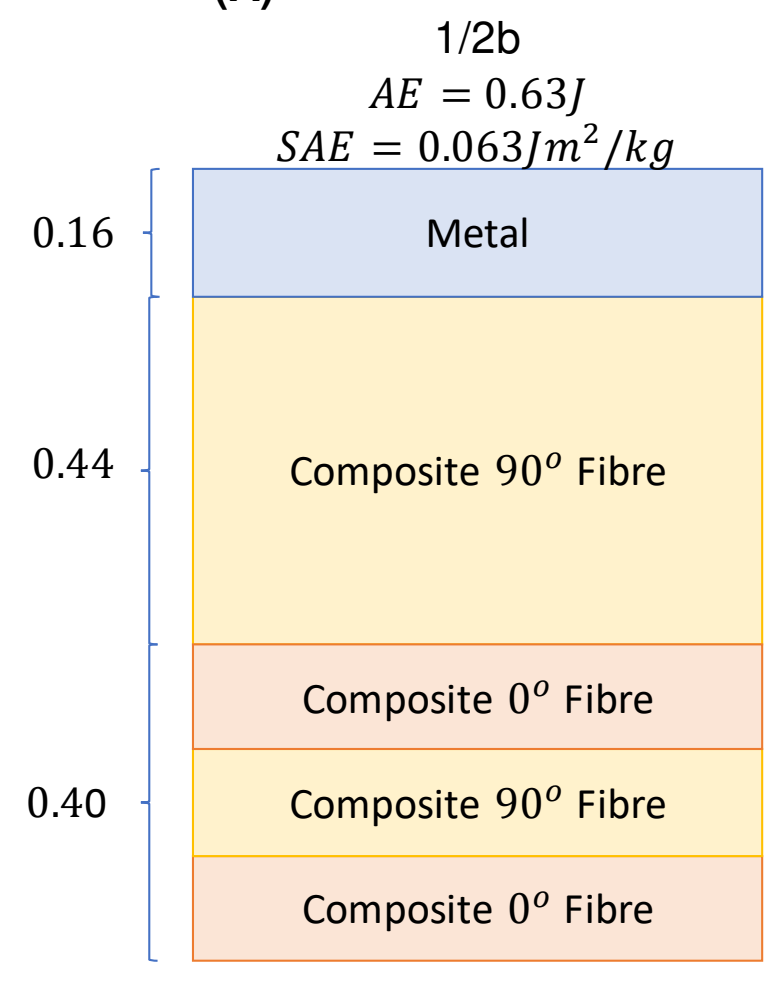

(B)

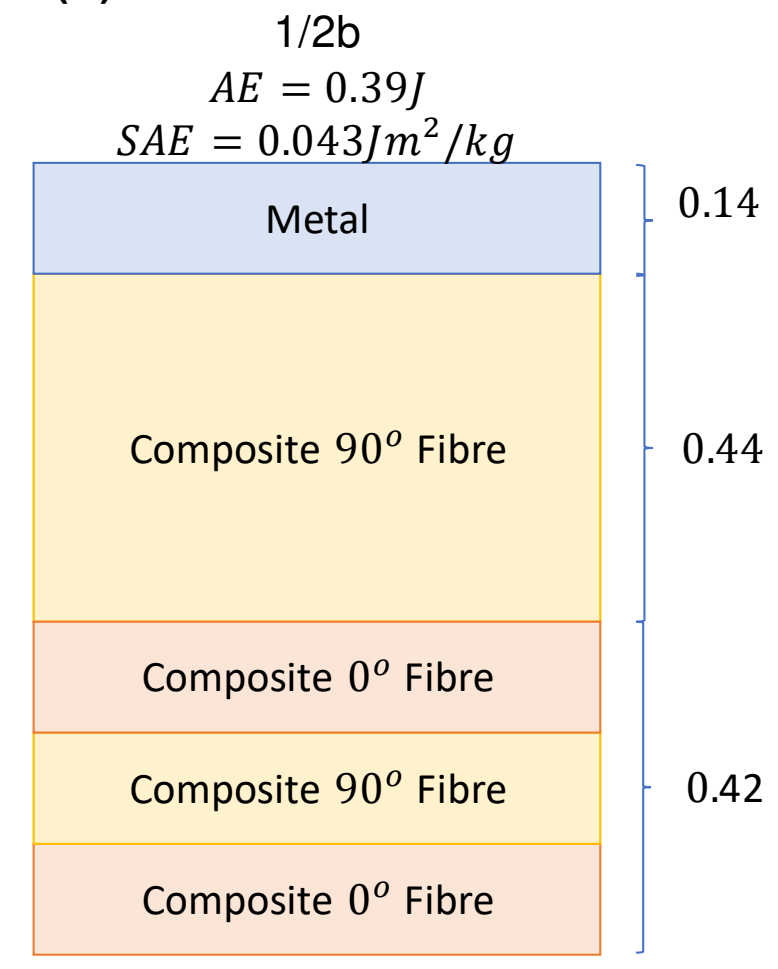

Figure 3-7 Effect of ply thickness on impact properties on GA-2 configuration

For the configurations with alternating plies such as the GA-3 configuration, the thickness of the second ply was seen to converge to a maximum. Unlike in the GA-2 configuration, individual ply thicknesses of the third layer had a strong influence on the performance. It was noticed that the configurations with thinner plies exhibited a larger 
area of delamination allowing for more energy to be absorbed. This is similar to the findings made by Saito et al. [15] whilst a thicker first and second ply was noticed to maximise energy absorption. Figure 3-8 shows the individual ply thickness for best performing GA-3 and GA-4 configuration. The results showed a similar thickness for both configurations. However, in the GA-4 configuration, the thickness of the middle metallic ply was higher than the composite ply in the GA-3 configuration. This resulted in the GA-4 configuration having a higher mass resulting in a similar SAE value to that of the GA-3 configuration despite absorbing higher impact energy (AE).

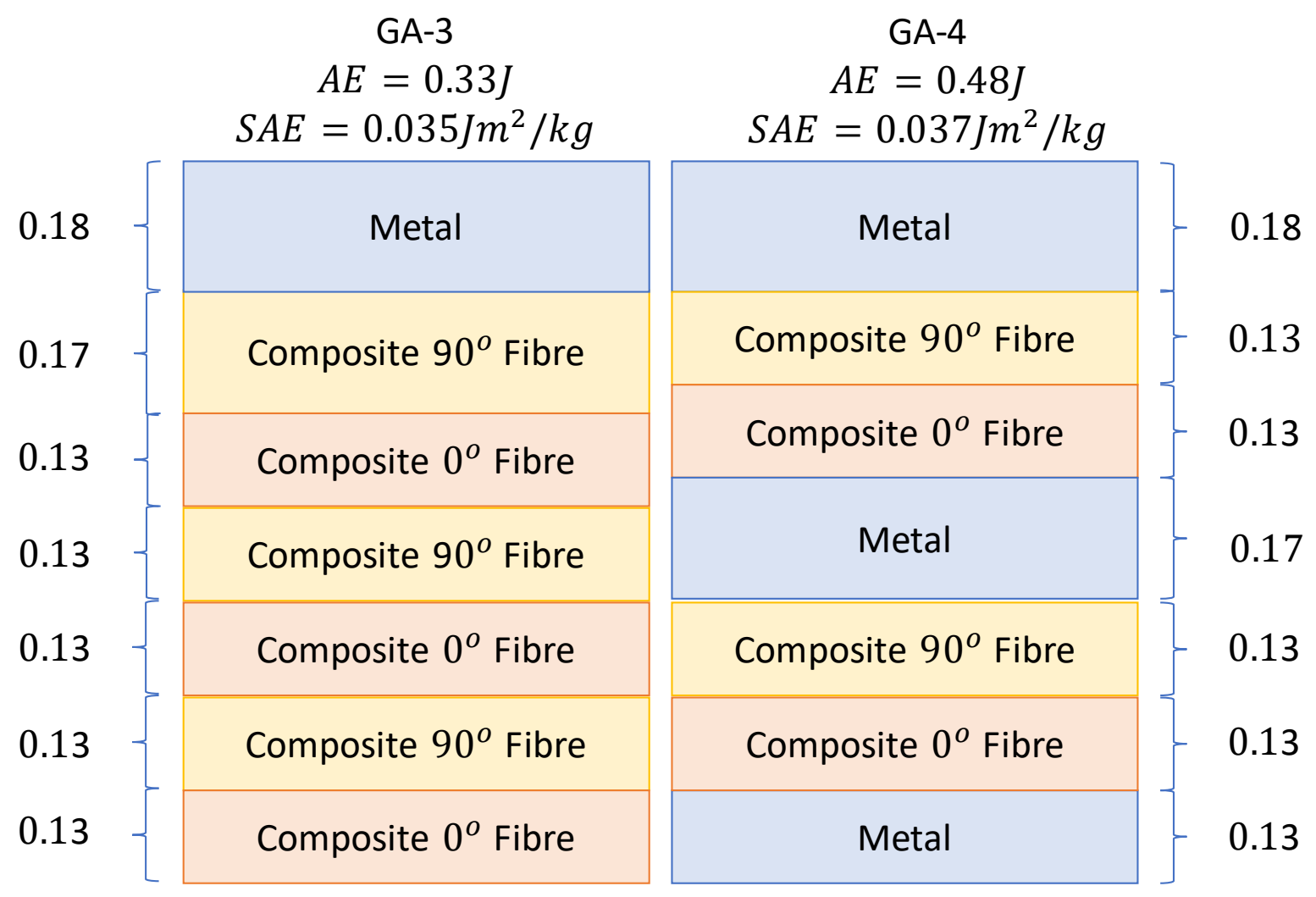

Figure 3-8 Individual ply thickness for GA-3 and GA-4 configurations with the highest SA 


\section{Part II: Verification and Validation}

\subsection{Verification Using 3D Numerical Model}
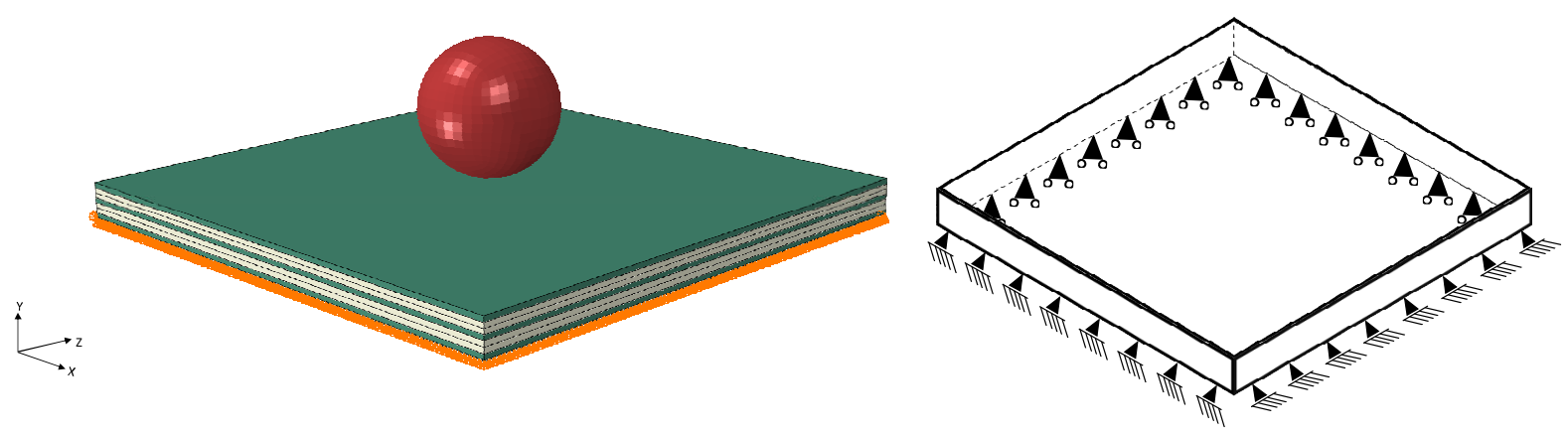

Figure 4-1 Assembled 3D model

To verify the different configurations proposed from the GA optimised study, the results of Part I was applied to a 3D model to provide a more realistic impact scenario. This model would also help to reduce the effects of the boundary condition on the behaviour of the laminate that resulted in configurations with thick $90^{\circ}$ layers exhibiting higher energy absorption property than those with more alternating 0/90 layers as described by Seyed Yaghoubi and Liaw [17] and Laliberte [32].

The laminate was modelled as a square plate with $100 \mathrm{~mm}$ sides. The thickness chosen was selected from the best configuration obtained from the optimisation discussed in section 3.1. Figure 4-1 shows the assembled 3D model. As with the stripmodel, each ply was modelled individually. The material and interaction properties described in section 3 were used except for the mass of the impactor. This was set to $1.8 \mathrm{~kg}$ resulting in an initial kinetic energy of $90 \mathrm{~J}$. Pinned boundary condition were applied to the edges of the bottom ply as shown in Figure 4-1. To prevent stretching of the plate due to bending, one side was fixed whilst the opposing sides were allowed to translate in their respective direction. 
GA-1

\begin{tabular}{|c|}
\hline Metal \\
\hline Composite $90^{\circ}$ Fibre \\
\hline Composite $0^{\circ}$ Fibre \\
\hline
\end{tabular}

\section{GA-3}

\begin{tabular}{|c|}
\hline Metal \\
\hline Composite $90^{\circ}$ Fibre \\
\hline Composite $0^{\circ}$ Fibre \\
\hline Composite $90^{\circ}$ Fibre \\
\hline Composite $0^{\circ}$ Fibre \\
\hline Composite $90^{\circ}$ Fibre \\
\hline Composite $0^{\circ}$ Fibre \\
\hline
\end{tabular}

GA-2

\begin{tabular}{|c|}
\hline Metal \\
\hline Composite $90^{\circ}$ Fibre \\
\hline Composite $0^{\circ}$ Fibre \\
\hline Composite $90^{\circ}$ Fibre \\
\hline Composite $0^{\circ}$ Fibre \\
\hline
\end{tabular}

GA-4

\begin{tabular}{|c|}
\hline Metal \\
\hline Composite $90^{\circ}$ Fibre \\
\hline Composite $0^{\circ}$ Fibre \\
\hline Metal \\
\hline Composite $90^{\circ}$ Fibre \\
\hline Composite $0^{\circ}$ Fibre \\
\hline Metal \\
\hline
\end{tabular}

Figure 4-2 Plies Configuration Modelled in 3D

The four configurations shown in Figure 4-2 obtained from the optimisation were simulated and compared. The force-displacement graph for the different configurations is shown in Figure 4-3. One item to highlight is the influence of a constrained delamination growth (like those in the 2D strip model) on the impact response of the plate. To illustrate, in the strip model, a laminate composed of only $0^{\circ}$ plies produced different impact response to that of a laminated with only $90^{\circ}$ plies. However, in the 3D models, both laminates produced the same response, due to symmetry. This is why it is imperative to check the selected optimised configurations in 3D. Although this behaviour of the strip model affected the energy absorption properties and thus the optimisation process, the effect was minimal when compared to the other factors affecting the impact property of the FMLs. 


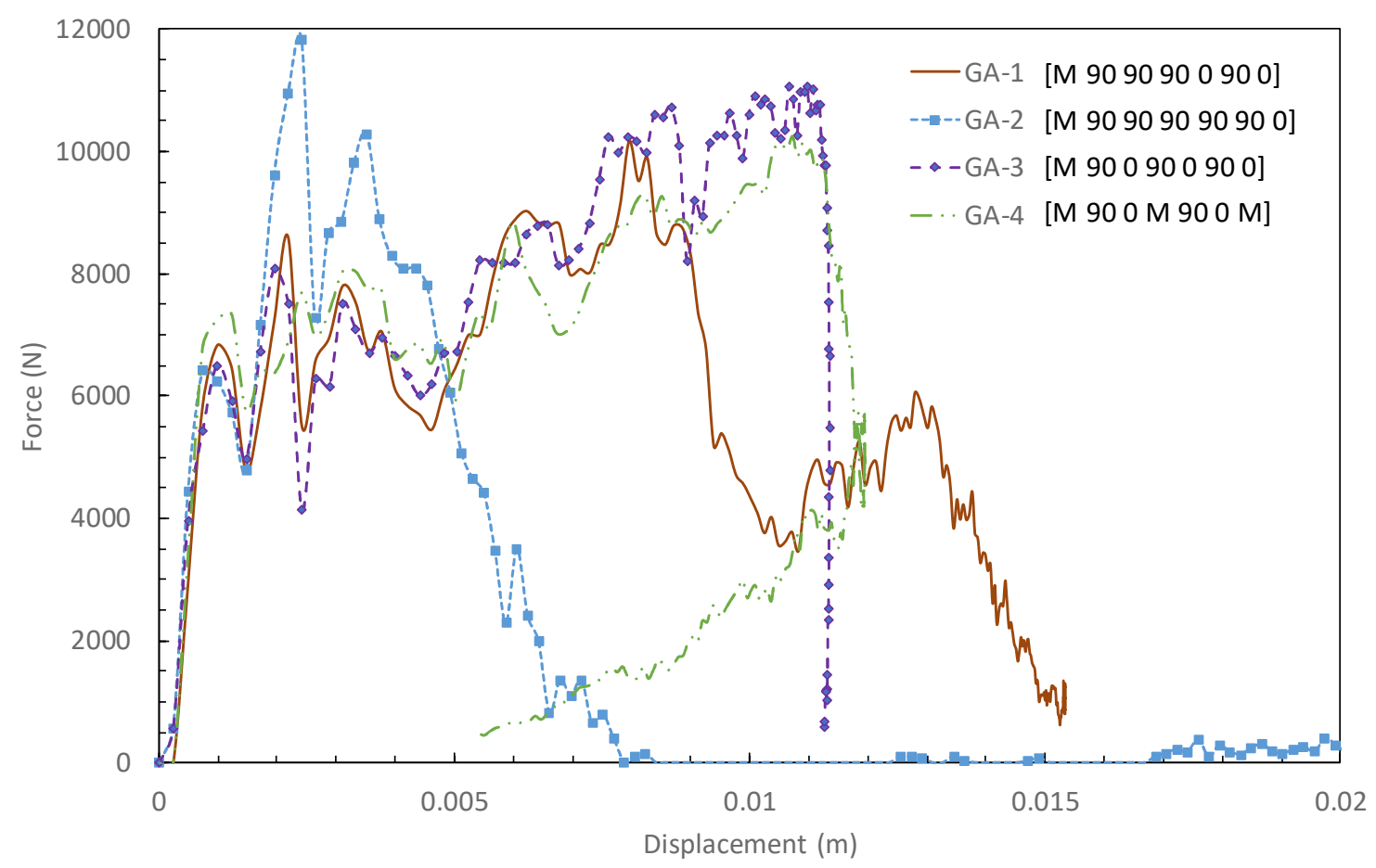

Figure 4-3 3D models force-displacement graph

The results showed that the GA-1 configuration absorbed the least impact energy. This contradicts the results obtained from the strip model (Figure 3-5). However, as stated earlier this was to be expected due to the small delamination area available in this configuration. Shown in Figure 4-7, the GA-1 configuration, experienced a large split through the thick 90 layers. Similar cracking was also observed in the thick $90^{\circ}$ layer of the GA-2 configuration, however, the alternative 0/90 layer helped to minimise this effect, converting the loss in stiffness to large delamination on the dissimilar interfaces of the plate. For this reason configuration (GA-2) produced by the GA function absorbed the highest impact energy and produced the highest SAE value as shown in Figure 4-4.

These results highlight that placing a thick compliant composite layer immediately after the metallic layer on the impact side has a strong benefit to the energy absorption mechanism of the entire plate. However, unlike the results obtained from the stripmodel, ply failure of the non-impacted layers occurred much earlier after impact. The ply failure led to delamination between the non-impacted ply and the neighbouring ply. The delamination restricted the progression of the failure of the non-impacted ply allowing for more energy absorption. 


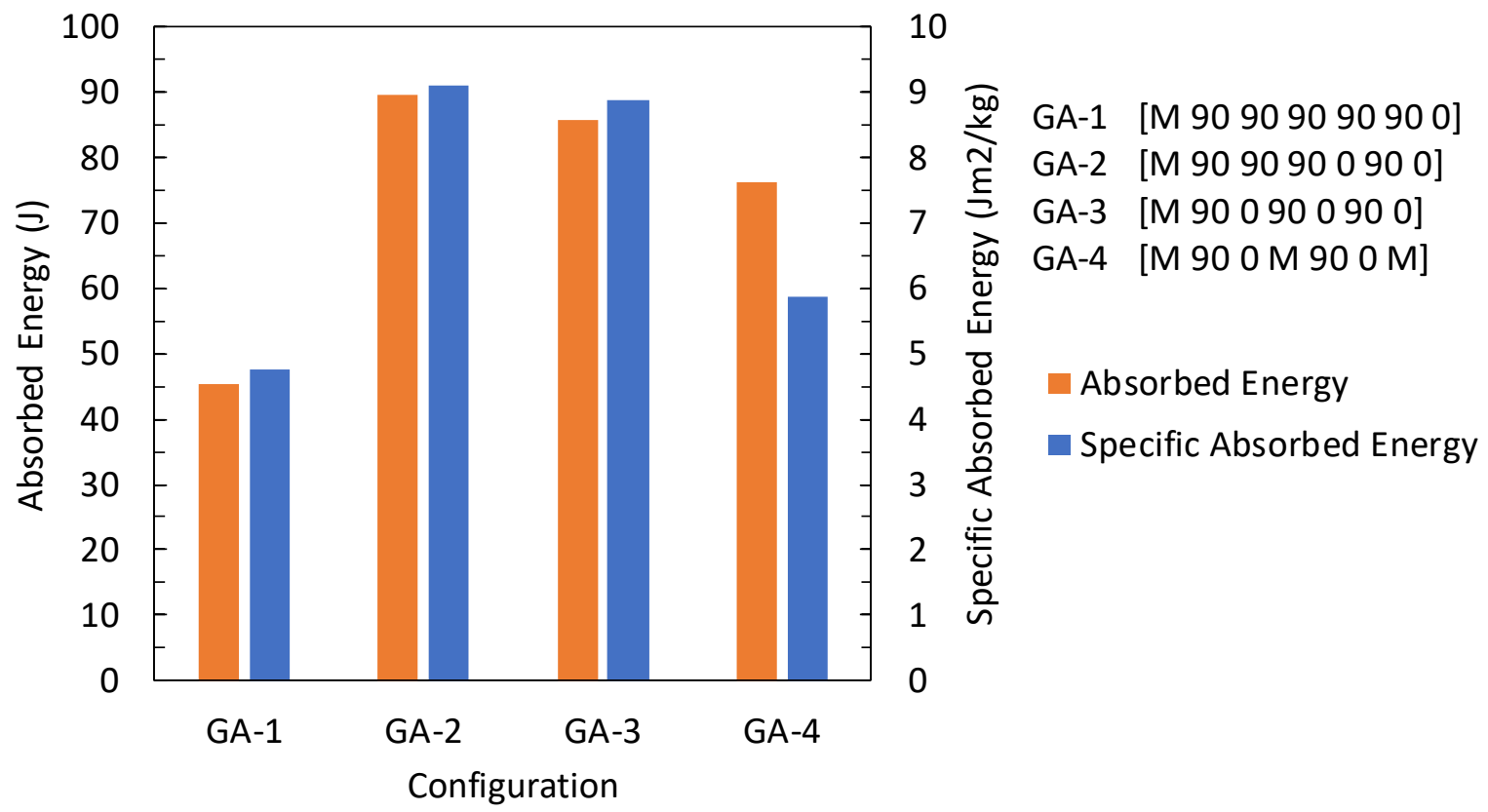

Figure 4-4 Absorbed and specific absorbed energy for 3D models

The GA-4 configuration exhibited the highest stiffness, it was the only configuration in which the impactor rebounded off the laminate. The delamination on this laminate was similar to that seen in the GA-2 configuration. However, adding the extra metallic plies provided better impact resistance rather than absorption properties to the laminate. The higher number of metallic plies also increased the overall mass of the laminate and thus a low SAE.

The GA-3 configuration exhibited the second-highest impact absorption properties. The results from the simulation showed that the GA-3 configuration reacted similarly to the GA-2 configuration. This showed that delamination played an important role in absorbing the impact energy as expected, thus producing the highest delamination area.

Figure 4-5 and Figure 4-6 shows the 3 stages of the damage sequence for the GA-1 and GA-3 configuration respectively. The position of each stage is marked on the force-displacement graph. Figure 4-7 shows the delamination in the different configurations. 


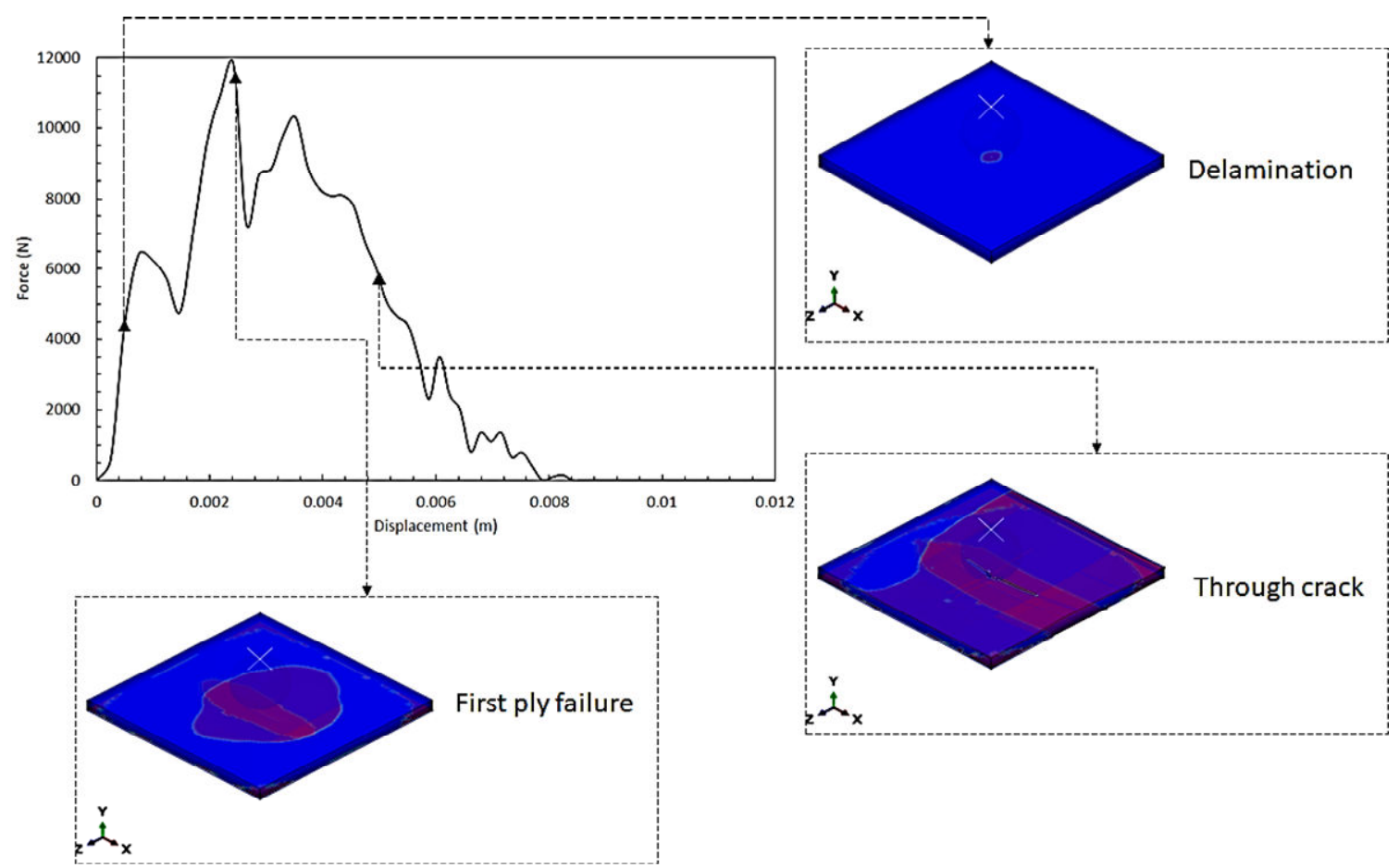

Figure 4-5 Damage sequence for GA-1 configuration

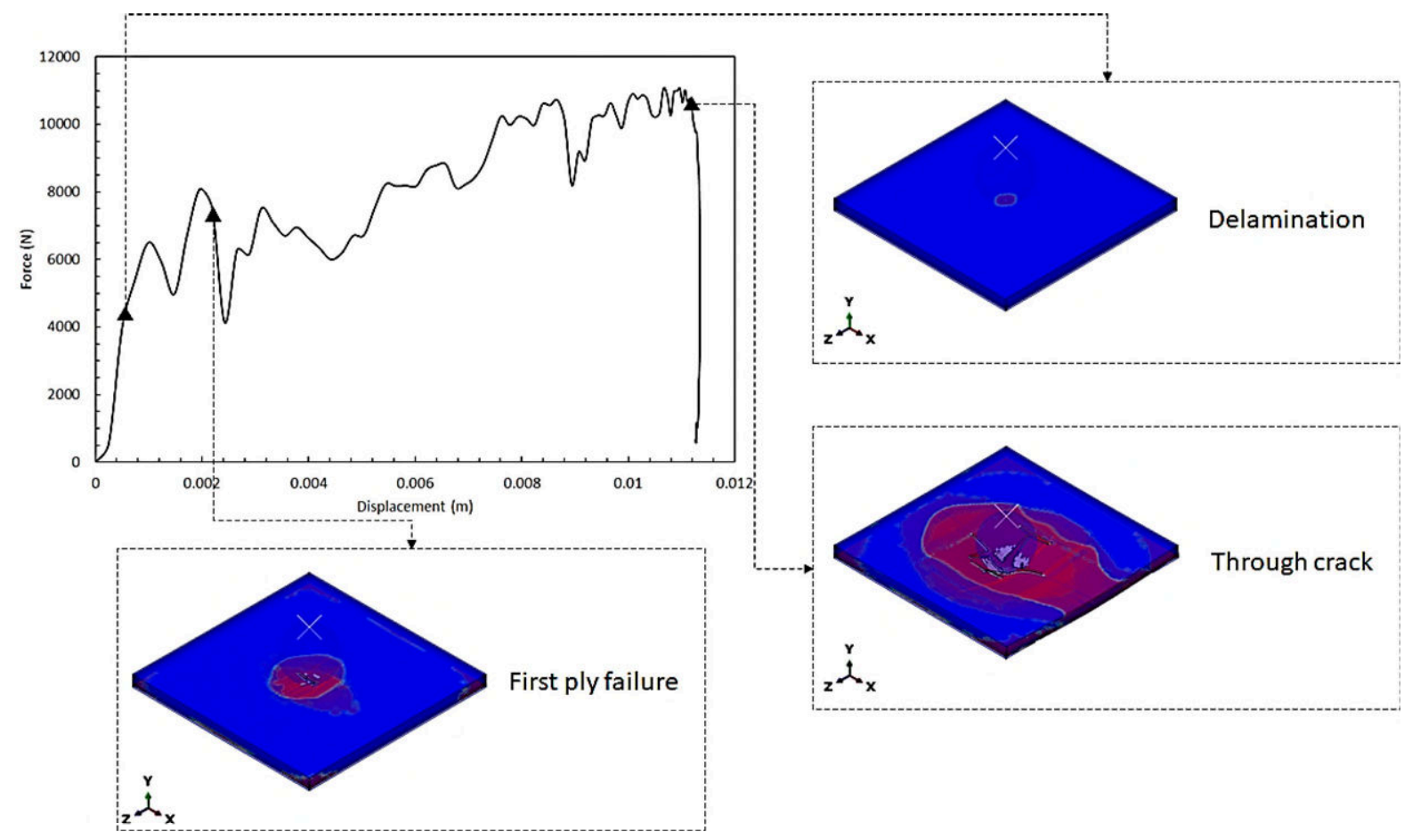

Figure 4-6 Damage sequence for GA-3 configuration 

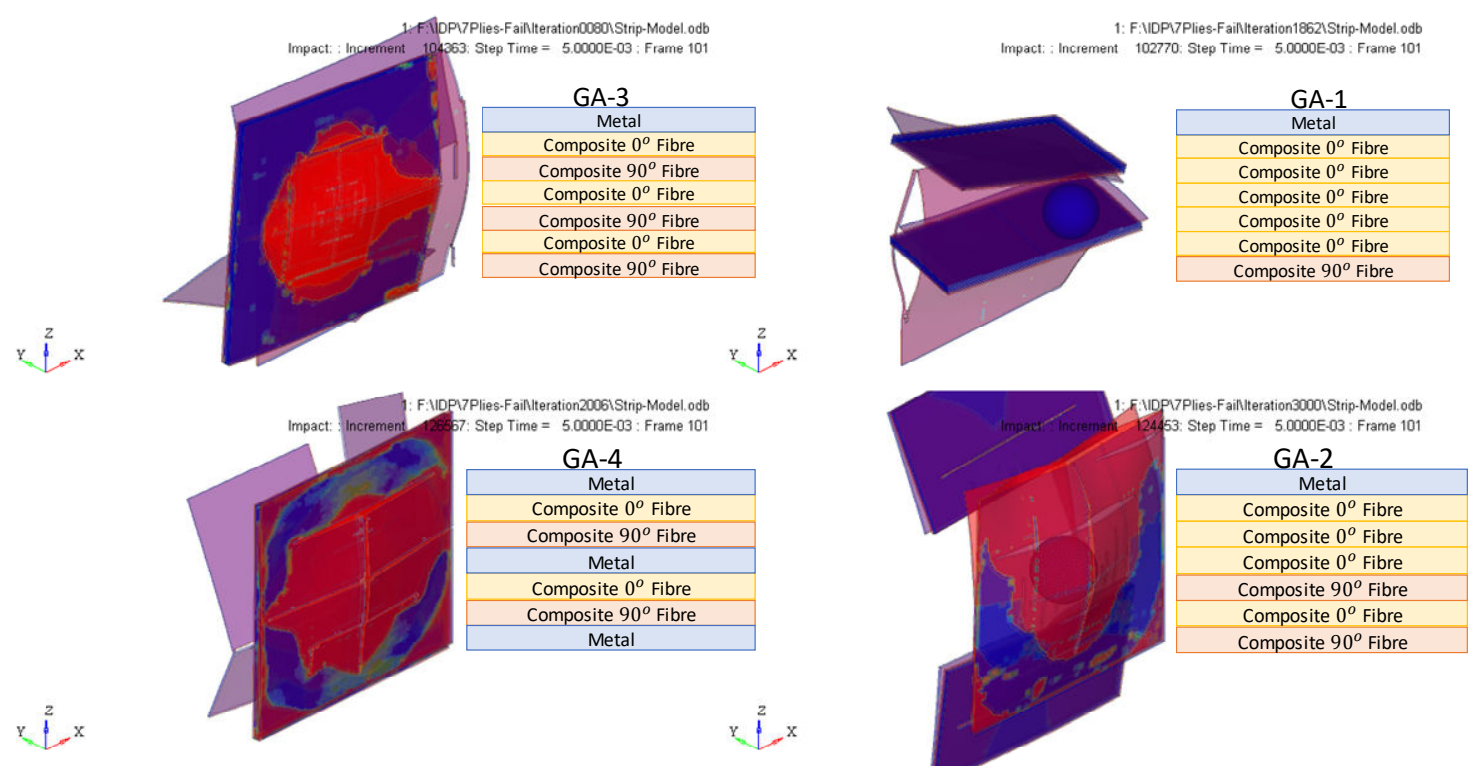

Figure 4-7 Delamination in 3D models

\subsection{Validation against Experimental Data}

In this section, the optimised FML configuration proposed here will be validated against a standard FML configuration experimentally tested in literature. Experiments carried out by Seyed Yaghoubi [17] showed that a 3/2 cross-ply configuration offered the maximum impact resistance compared to the other configurations. The validation exercise in this paper will compare numerically the $3 / 2$ cross-ply FML configuration describe in [1] to the GA optimised configuration (GA-2). Table 8 to Table 12 shows the material properties used to define the models.

\section{Table 8}

Composite S2-Glass/FM94 Elastic Properties [29]

\begin{tabular}{ll}
\hline Parameter & Value \\
\hline Mass density $\rho$ & $2000 \mathrm{kgm}^{-3}$ \\
Young modulus, fibre direction $\left(E_{1}\right)$ & $50 \mathrm{GPa}$ \\
Young modulus, transverse direction & $9.0 \mathrm{GPa}$ \\
$\left(E_{2}, E_{3}\right)$ & \\
In-plane shear modulus $\left(G_{12}, G_{23}\right)$ & $3.5 \mathrm{GPa}$ \\
Transverse shear Modulus $\left(G_{13}\right)$ & $3.0 \mathrm{GPa}$ \\
Poisson's ratio $\left(v_{12}\right)$ & 0.32
\end{tabular}



Poisson's ratio $\left(v_{13}\right)$
0.32
Poisson's ratio $\left(v_{23}\right)$
0.04

\section{Table 9}

Composite S2-Glass/FM94 Strength Properties [29]

\begin{tabular}{ll}
\hline Parameter & Value \\
\hline Tensile strength, fibre direction $\left(X_{T}\right)$ & $2 G P a$ \\
Compressive strength, fibre direction $\left(X_{C}\right)$ & $550 M P a$ \\
Tensile strength $\left(Y_{T}\right)$ & $43 M P a$ \\
Compressive strength $\left(Y_{C}\right)$ & $90 M P a$ \\
Shear strength (in-plane), $\left(S_{12}\right)$ & $93 M P a$ \\
Shear strength $\left(S_{23}\right)$ & $50 M P a$ \\
$\alpha$ & 0 \\
\hline
\end{tabular}

\section{Table 10}

Mechanical Properties of Aluminium 2024-T3 [23]

\begin{tabular}{ll}
\hline Parameter & Value \\
\hline Young's modulus $(E)$ & $73.1 \mathrm{GPa}$ \\
Poisson's ratio $(v)$ & 0.33 \\
Mass density $(\rho)$ & $2780 \mathrm{Kgm}^{-3}$ \\
\hline
\end{tabular}

\section{Table 11}

Plasticity Parameters of Aluminium 2024-T3 [33]

\begin{tabular}{ll}
\hline Plastic Strain & Yield Stress \\
\hline$A$ & $265 M P a$ \\
$B$ & $426 M P a$ \\
$n$ & 0.34 \\
\hline
\end{tabular}




\section{Table 12}

Johnson-Cook Damage Parameters of Aluminium 2024-T3 [33]

\begin{tabular}{ll}
\hline Parameter & Value \\
\hline$d_{1}$ & 0.13 \\
$d_{2}$ & 0.13 \\
$d_{3}$ & -1.5 \\
\hline
\end{tabular}

Figure 4-8 shows the configuration and dimension (percentage of the overall length of the laminate) used for the comparison. The thickness of each ply was selected using the optimised ratio shown in Figure 3-7a. The overall laminate thickness of $1.93 \mathrm{~mm}$ as described in [1] was enforced. The model definitions were created using the same procedure described in section 2. However, the mass of the impactor was set to $6.14 \mathrm{~kg}$ to match the experimental procedure described in [1].

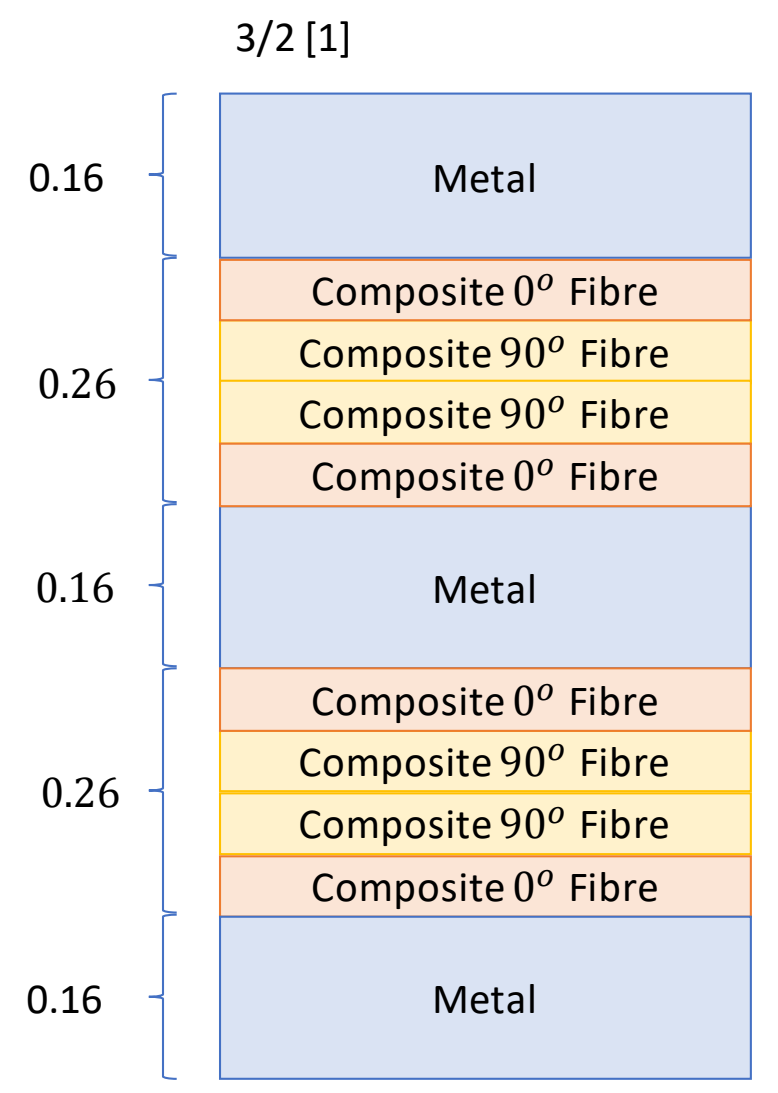

(a) Standard FML configuration
GA-2

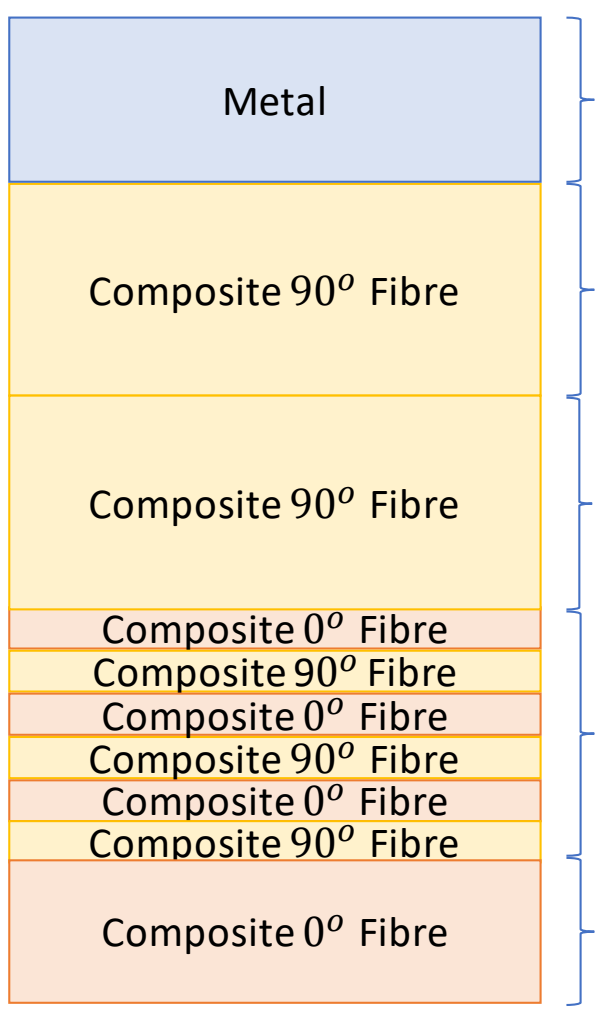

Figure 4-8 Verification models 
The numerical results are shown in Figure 4-9 and Figure 4-10. The numerical model in this investigation produced a very good agreement in the initial stiffness of the plate relative to the experimental data however the sequence of damage events in the experimental appears to differ significantly meaning the peak loads are not captured well. Many issues may be causing this, including assumed material properties and damage parameters used in table 8-12. Furthermore, a more robust failure criterion for the composite layers will be needed to get a better agreement. The interactive FRP composite failure criterion by Hashin [34] used here is a stress-based empirical model which require an element of curve-fitting to ensure their accuracy is maintained. A more robust and comprehensive failure criterion utilises physical-based stress analysis to determine the various failure mechanisms such as Puck-Schurmann [35], Davila-Camanho [36] or Pinho et. al. [37]. Although an important to investigate the accuracy of such phenomenological failure criteria to simulate the FML plate impacts it is beyond the scope of this paper. However, results produced here have some agreement with experimental work and therefore an acceptable validation method to compare the two configurations numerically.

From the numerical results, the energy absorbed by the optimised configuration is shown to be $4.8 \%$ higher than that of the standard configuration. The specific absorbed energy of the optimised configuration was also $17.8 \%$ higher than the standard configuration. However, as seen from the force-displacement graph (Figure 4-9), similarly to the results shown in Figure 4-3 the impactor did not perforate the 3/2 laminate. Overall, it is shown that the presented GA optimisation procedure has produced an FML configuration with significant improvement in the SEA over standard FML configurations. 


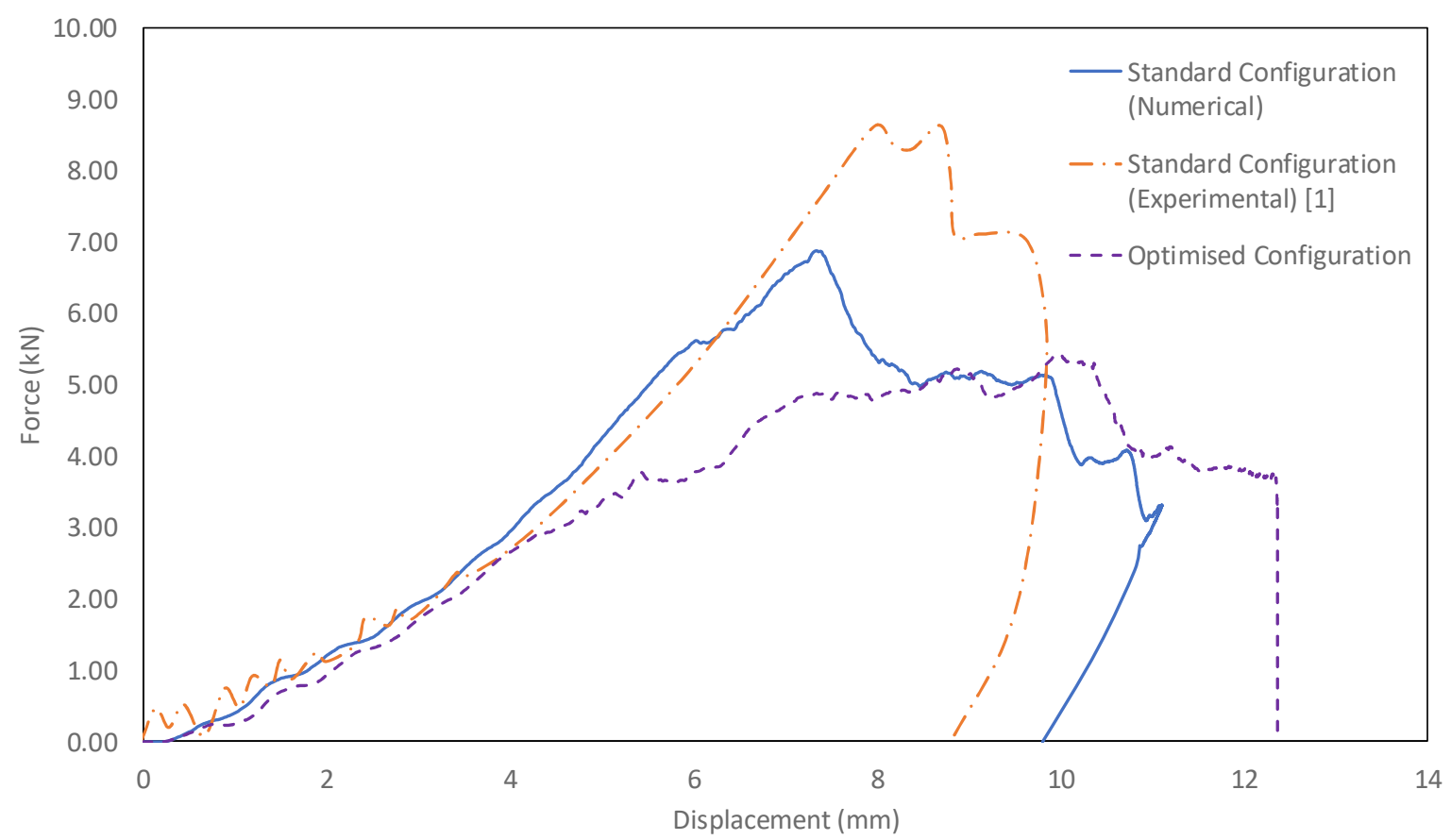

Figure 4-9 Force-displacement comparison graph with standard FML configuration

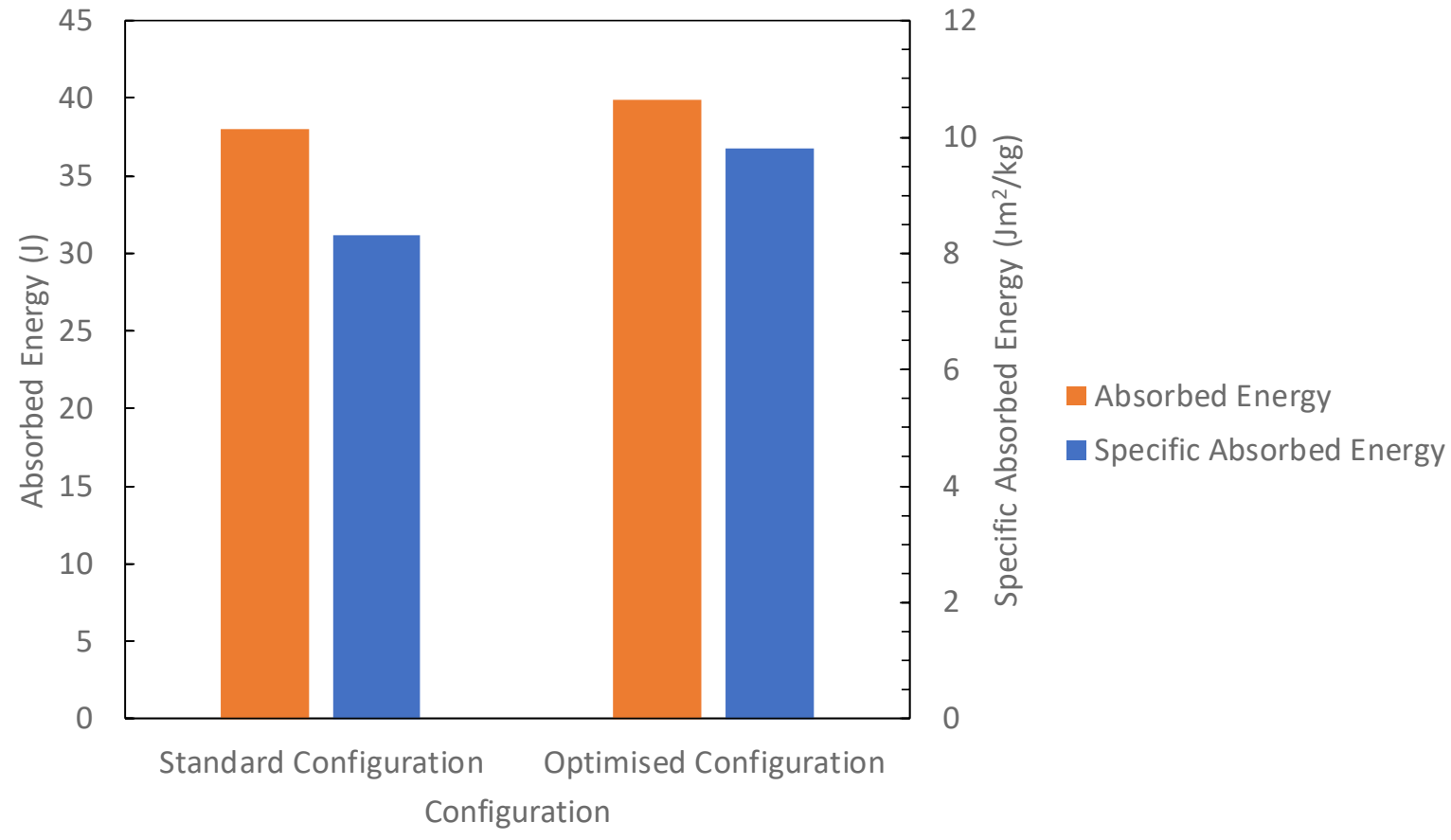

Figure 4-10 Absorbed and specific absorbed energy comparison with a standard FML configuration

\section{Conclusion}

This project studied the effect of the layup configuration on the impact properties of Fibre Metal Laminates (FMLs). An optimisation procedure was presented which 
utilised genetic algorithm (GA) to search for a configuration for maximum specific energy absorption properties. The parameters used to carry out this study included changing individual layer thicknesses, materials and arrangements. Each configuration was numerically analysed using ABAQUS explicit with a high fidelity model capable of capturing metal plastic deformation and failure, composite failure and delamination.

The results showed that to achieve maximum specific absorbed energy, the FML laminate should be comprised of a single metallic ply on the impacted side with alternating composites plies stacked beneath it. The results showed that placing the metallic ply as the impacted ply allowed for energy absorption through the plastic deformation before triggering the other failure modes in the composite layers. In terms of the thickness of the ply, the results suggest using a thick compliant composite layer (less than $44 \%$ of overall plate thickness), directly after the metallic ply has some benefit to the overall performance. The results also showed that the fibre direction of this compliant layer played no role in the energy absorption properties of the laminate.

The composite layer that follows after the second layer should have alternating fibre direction to allow for energy absorption through delamination at dissimilar interfaces. It was also noticed that the thickness variations of these plies offered negligible influence in the energy-absorbing properties of the FML.

Finally, a validation exercise highlighted that the optimum configuration produced exhibited up to $18 \%$ improvement in the specific energy absorption of the plate over standard FML configurations.

The optimisation portion of this study was done on a pseudo-2D strip model. It was shown that the boundary conditions of a full 3D plate have some influence on the performance, specifically on the thickness of the second compliant composite layer. Although computationally expensive, future work may apply the same optimisation procedure directly to a full 3D model as well as exploring a wider range of thickness and fibre orientation variations of individual layers.

The modelling strategy used here captured key damage mechanisms of an FML material. However, the effect of the material properties, different metal and composite damage and failure models was not studied in this paper. As a result, improvements 
to both material properties and numerical modelling methods may produce more accurate results and thus could be considered in future studies.

\section{Data Availability}

The raw/processed data required to reproduce these findings cannot be shared at this time as the data also forms part of an ongoing study.

\section{References}

[1] Seyed Yaghoubi A, Liu Y, Liaw B. Stacking sequence and geometrical effects on low-velocity impact behaviors of GLARE 5 (3/2) fiber-metal laminates. Thermoplast Compos Mater 2012;25:223-47.

[2] Hoo Fatt MS, Lin C, Revilock DM, Hopkins DA. Ballistic impact of GLARETM fiber-metal laminates. Compos Struct 2003;61:73-88.

[3] Cortés $P$, Cantwell WJ. The impact properties of high-temperature fiber-metal laminates. J Compos Mater 2007;41:613-32.

[4] Marsh G. Composites lift off in primary aerostructures. Reinf Plast 2004:22-7.

[5] Seyed Yaghoubi A, Liaw B. Thickness influence on ballistic impact behaviors of GLARE 5 fiber-metal laminated beams: Experimental and numerical studies. Compos Struct 2012;94:2585-2598.

[6] Marsh G. Airframers exploit composites in battle for supremacy. Reinf Plast 2005:26-32.

[7] Sadighi M, Alderliesten RC, Benedictus R. Impact resistance of fiber-metal laminates: A review. Int J Impact Eng 2012;49:77-90.

[8] Das R, Chanda A, Brechou J, Banerjee A. Impact behaviour of fibre-metal laminates. Dyn. Deform. Damage Fract. Compos. Mater. Struct., Elsevier; 2016, p. 491-542.

[9] Cortes P. The Fracture Properties of a Fiber Metal Laminate Based on a SelfReinforced Thermoplastic Composite Material. Polym Compos 2014;35:42734.

[10] Wu HF, Wu LL, Slagter WJ, Verolme JL. Use of rule of mixtures and metal volume fraction for mechanical property predictions of fibre-reinforced 
aluminium laminates. J Mater Sci 1994;29:4583-91.

[11] Ghasemi FA, Raissi S, Malekzadehfard K. Analytical and mathematical modeling and optimization of fiber metal laminates (FMLs) subjected to lowvelocity impact via combined response surface regression and zero-one programming. Lat Am J Solids Struct 2013;10:391-408.

[12] Kaboglu C, Mohagheghian I, Zhou J, Guan Z, Cantwell W, John S, et al. Highvelocity impact deformation and perforation of fibre metal laminates. J Mater Sci 2018;53:4209-28.

[13] Langdon GS, Lemanski SL, Nurick GN, Simmons MC, Cantwell WJ, Schleyer GK. Behaviour of fibre-metal laminates subjected to localised blast loading: Part I-Experimental observations. Int J Impact Eng 2007;34:1202-22.

[14] Choi HY, Wang HS, Chang FK. Effect of Laminate Configuration and Impactor's Mass on the Initial Impact Damage of Graphite/Epoxy Composite Plates Due to Line-Loading Impact. J Compos Mater 1992;26:804-27.

[15] Saito H, Morita M, Kawabe K, Kanesaki M, Takeuchi H, Tanaka M, et al. Effect of ply-thickness on impact damage morphology in CFRP laminates. J Reinf Plast Compos 2011;30:1097-106.

[16] Sharma AP, Khan SH, Kitey R, Parameswaran V. Effect of through thickness metal layer distribution on the low velocity impact response of fiber metal laminates. Polym Test 2018;65:301-12.

[17] Seyed Yaghoubi A, Liaw B. Effect of lay-up orientation on ballistic impact behaviors of GLARE 5 FML beams. Int J Impact Eng 2013;54:138-48.

[18] Alderliesten R, Hagenbeek M, Homan JJ, Hooijmeijer PA, De-Vries TJ, Vermeeren CAJR. Fatigue and Damage Tolerance of Glare. Appl Compos Mater 2003;10:223-42.

[19] Fan J, Guan ZW, Cantwell WJ. Numerical modelling of perforation failure in fibre metal laminates subjected to low velocity impact loading. Compos Struct 2011;93:2430-6.

[20] Tsartsaris N, Meo M, Dolce F, Polimeno U, Guida M, Marulo F. Low-velocity impact behavior of fiber metal laminates. J Compos Mater 2011;45:803-14. 
[21] Zhu S, Chai GB. Low-velocity impact response of fibre-metal laminates Experimental and finite element analysis. Compos Sci Technol 2012;72:1793802.

[22] Zhang DN, Shangguan QQ, Xie CJ, Liu F. A modified Johnson-Cook model of dynamic tensile behaviors for 7075-T6 aluminum alloy. J Alloys Compd 2015;619:186-94.

[23] Metals Handbook, Vol.2 - Properties and Selection: Nonferrous Alloys and Special-Purpose Materials, ASM International 10th Ed. 1990.

[24] Camanho PP, Hallett SR. Numerical Modelling of Failure in Advanced Composite Materials. 1st ed. Woodhead Publishing; 2015.

[25] Lu X, Ridha M, Chen BY, Tan VBC, Tay TE. On cohesive element parameters and delamination modelling. Eng Fract Mech 2019;206:278-96.

[26] ASTM D5528 - 13 Standard Test Method for Mode I Interlaminar Fracture Toughness of Unidirectional Fiber-Reinforced Polymer Matrix Composites n.d. https://www.astm.org/Standards/D5528 (accessed June 14, 2018).

[27] ASTM D7905 / D7905M - 19 Standard Test Method for Determination of the Mode II Interlaminar Fracture Toughness of Unidirectional Fiber-Reinforced Polymer Matrix Composites n.d. https://www.astm.org/Standards/D7905 (accessed June 12, 2018).

[28] Yasaee M, Mohamed G, Pellegrino A, Petrinic N, Hallett SR. Strain rate dependence of mode II delamination resistance in through thickness reinforced laminated composites. Int J Impact Eng 2017;107:1-11.

[29] Al-Azzawi ASM, Kawashita LF, Featherston CA. Buckling and postbuckling behaviour of Glare laminates containing splices and doublers. Part 2: Numerical modelling. Compos Struct 2017;176:1158-69.

[30] MathWorks. How the Genetic Algorithm Works - MATLAB \& Simulink MathWorks United Kingdom n.d. https://uk.mathworks.com/help/gads/how-thegenetic-algorithm-works.html (accessed May 13, 2020).

[31] MathWorks. Find minimum of function using genetic algorithm - MATLAB ga MathWorks United Kingdom n.d. https://uk.mathworks.com/help/gads/ga.html (accessed May 13, 2020). 
[32] Laliberte JF, Poon C, Straznicky P V., Fahr A. Applications of Fiber-Metal Laminates. Polym Compos 2000;21:558-67.

[33] Kim Y. ENGN 2340 Final Project Simulating the mechanical behavior of AA2024-T3 with different strain rate and temperature . n.d.

[34] Hashin Z. Failure Criteria for Unidirectional Fiber Composites. J Appl Mech 1980;47:329. doi:10.1115/1.3153664.

[35] Puck A, Schürmann H. Failure analysis of FRP laminates by means of physically based phenomenological models. Compos Sci Technol 2002;62:1633-62. doi:10.1016/S0266-3538(01)00208-1.

[36] Davila CG, Camanho PP, Rose CA. Failure Criteria for FRP Laminates. J Compos Mater 2005;39:323-45. doi:10.1177/0021998305046452.

[37] Pinho ST, lannucci L, Robinson P. Physically-based failure models and criteria for laminated fibre-reinforced composites with emphasis on fibre kinking: Part I: Development. Compos Part A Appl Sci Manuf 2006;37:63-73. doi:10.1016/J.COMPOSITESA.2005.04.016. 


\title{
Cranfield University
}

2020-06-24

\section{pÿLay-up optimisation of fibre metal} laminates panels for maximum impact absorption

\author{
Arhore, Edore Godwin
}

Sage

pÿArhore EG, Yasaee M. (2020) Lay-up optimisation of fibre metal laminates panels for maximum impact absorption. Journal of Composite Materials, Volume 54, Issue 29, December 2020, pp. 4591-4609 https://doi.org/10.1177/0021998320937396

Downloaded from Cranfield Library Services E-Repository 